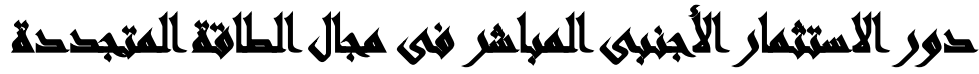

\author{
$\operatorname{los}$ \\ فاطمة الزهراء صلاح الدين محمود السعيد (')- السيد عطيه عبد الواحد(؟)

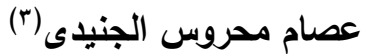

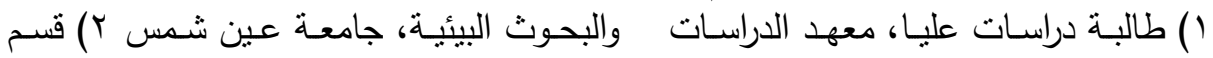

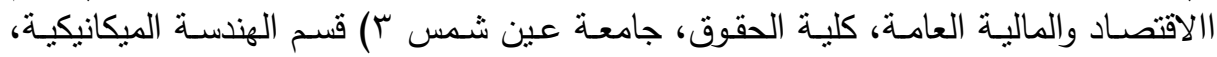
الأكاديمية العربية للعلوم التكنولوجيا والنقل البحرى.

\section{lill}

تهدف مصر فى خطتها هب •rم إلى زيادة مساهمة الطاقة المتجددة من إنتاج الطاقة

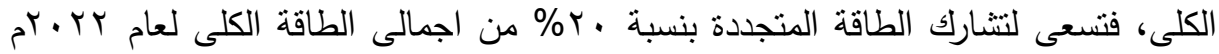

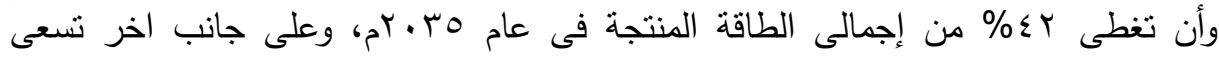

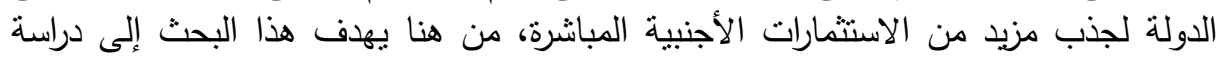

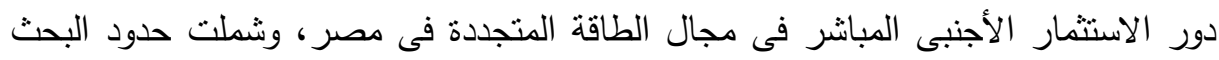

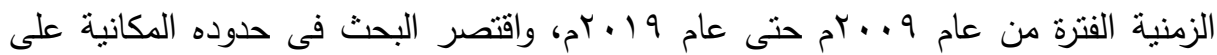

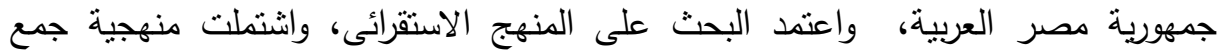

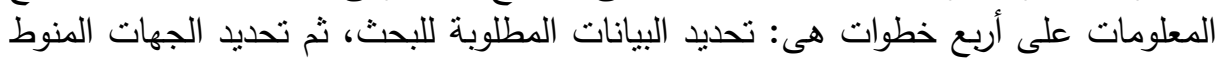
بها توفير هذه البيانات وهى الهيئة العامة للاستثمار والمناطق الحرة وهيئة تتمية واستخدام الطاقة الجديدة والمتجددة والثركة القابضة لكهرباء مصر وأيضا هيئة تتفيذ مشروعات

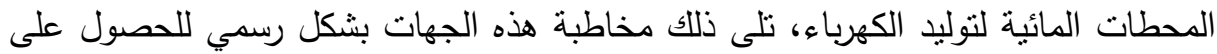

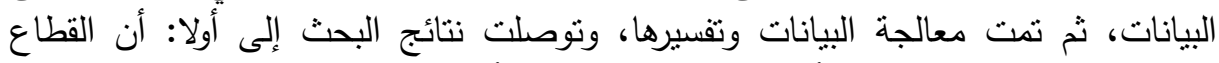

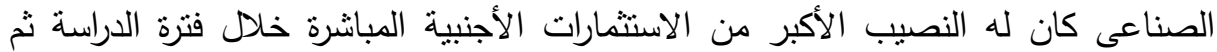

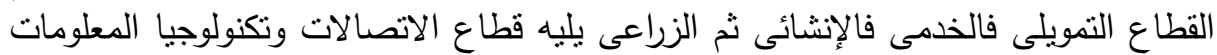

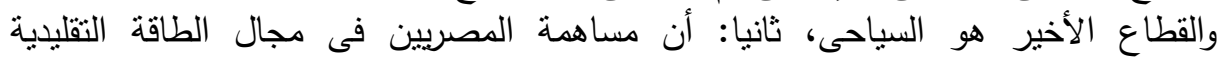

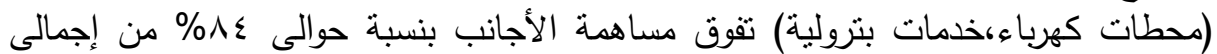

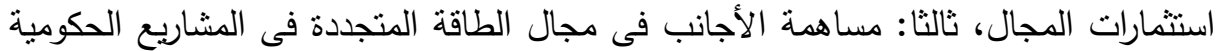

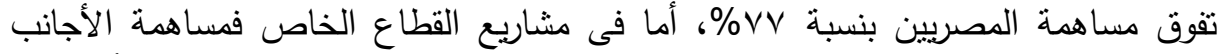

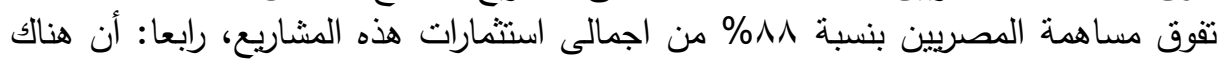

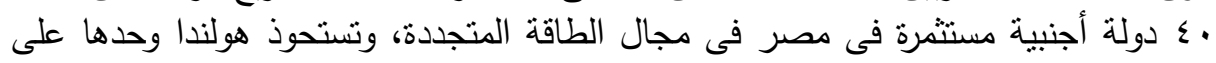

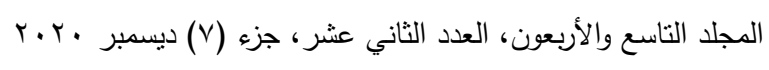


ومه من إجمالى الاستثمارات الأجنبية المباشرة فى مجال الطاقة المتجددة فى مصر.

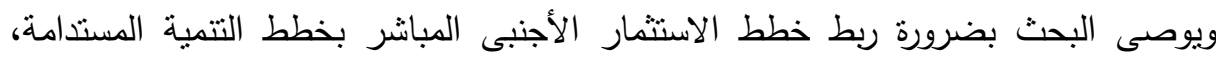

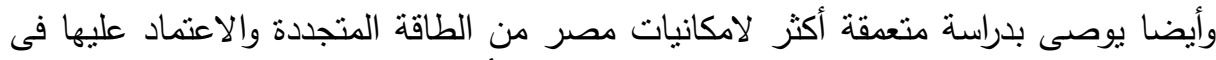

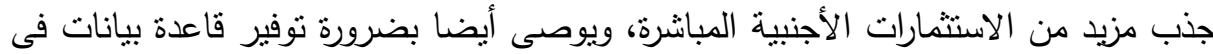

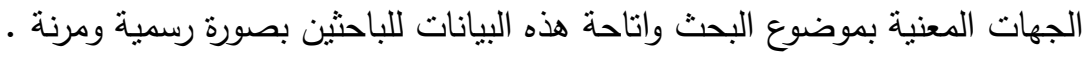

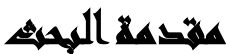

تلعب الاستثمارات الأجنبية المبانشرة دورا هاما في تتمية اقتصاديات الدول، فهي تعمل على زيادة القدرات الاتتاجية للدول ورفع معدل النمو الاقتصادي، كما تعد تدفقات الاستثمار

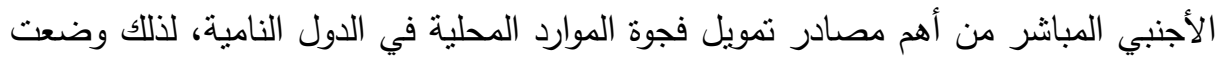
الدول النامية هدف جذب الاستثمار الاجنبي المباشر كأحد أهم القضايا على أجندتها

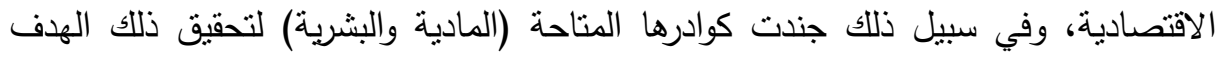
واستعانت بمختلف أدوات السياسة الاقتصادية بغية تحقيق هذا الهدف( محمد يونس عبده

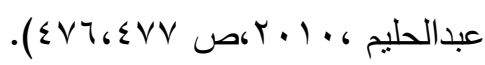
وبالنظر الي مصر نجد اهتمام الدولة البالغ بجذب الاستثمارات الأجنبية المباشرة بشكل

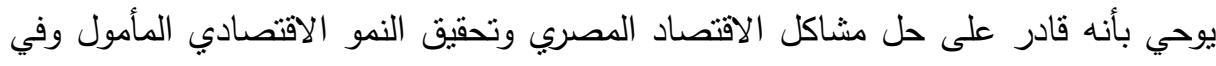
سبيل ذلك قدمت المزايا والاعفاءات التي تتجعه على التدفق، غير أن الدراسات الاقتصادية

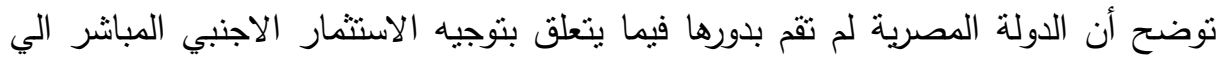

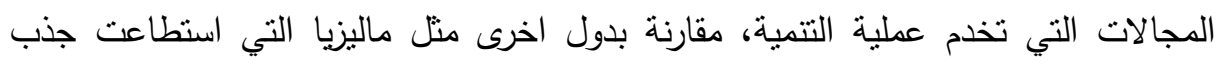

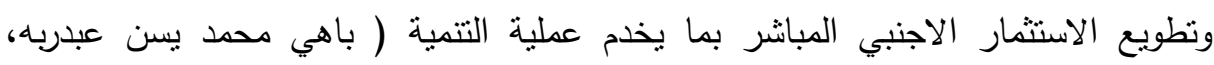

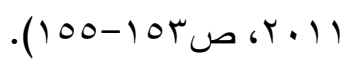

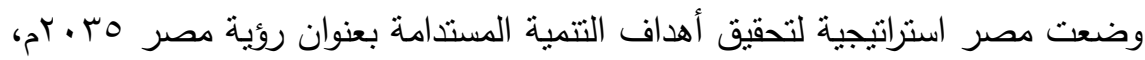

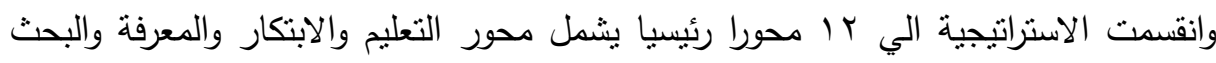

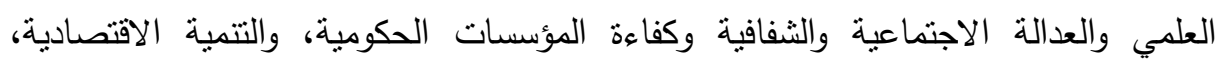

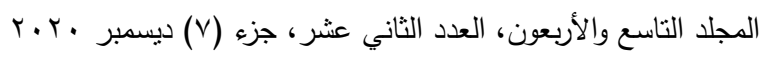

$$
\begin{aligned}
& \text { التزقيم الدولي 0826-1110 الاني }
\end{aligned}
$$


والتنمية العمرانية، والطاقة، والثقافة، والبيئة، والسياسة الداخلية، والأمن القومي والسياسة الخارجية والصحة ـ وقد حدد الاستراتيجية أهداف محور الطاقة خلال الخمسة عشر عاما ولها

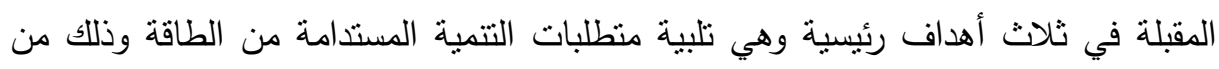

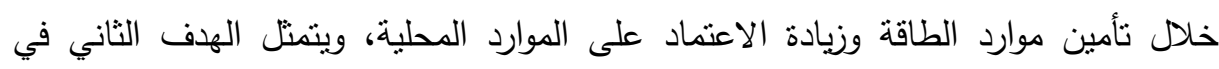
المساهمة الفعالة في دفع الاقتصاد والتتافسية الوطنية عن طريق الحد من الأثر البيئي لقطاع

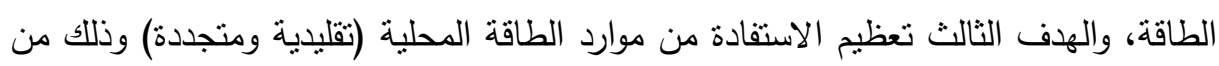

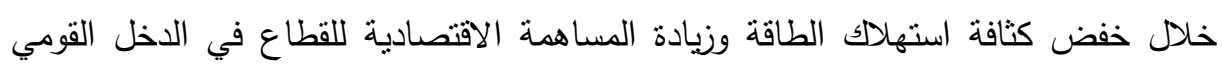
وجعلت مؤشر قياس هذا الهدف هو نسبة نمو الاستثمار في مجال الطاقة(استراتيجية التتمية

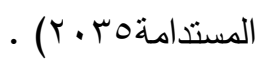

\section{هill}

رأت الحكومات المتتالية بعد ثورة يناير أن الاستثمار الأجنبي هو الحل الأمتل لمواجهة الصعوبات الاقتصادية التي يمر بها الاقتصاد المصري وذلك بسبب عدم كفاية روؤس الأموال

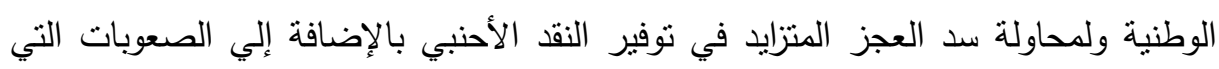

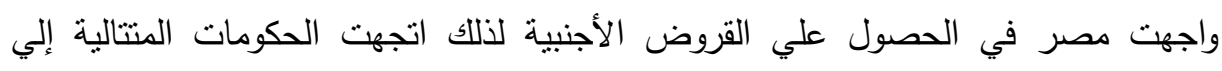
السعي إلي زيادة تدفقات الاستثمار الأجنبي المباشر من خلال تهيئة المناخ الاستثماري

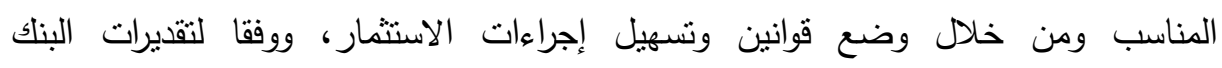
الدولي(الموقع الرسمي للبنك الدولي) فإن حجم تدفقات الاستثمار الأجنبي المباشر الوافدة إلي

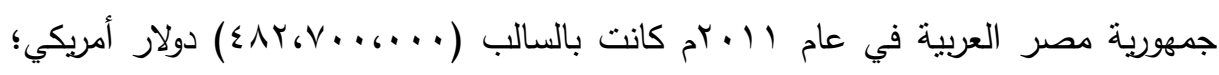
لذلك كان الاستثمار الأجنبي المباشر هدفا في حد ذاته بغض النظر عن النشاط الذي الني سيمارسه ودون أن تربط الدولة هذه الاستثمارات بأجندة اقتصادية واضحة تحدد الأولويات في

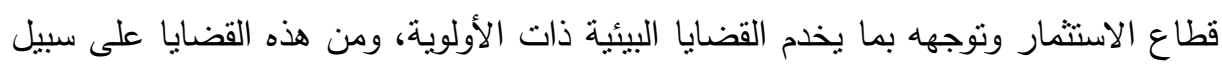

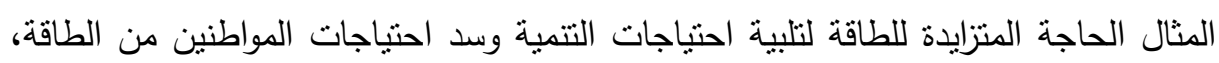

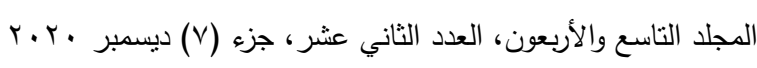

$$
\begin{aligned}
& \text { الترقيم الدولي 0826- ISSN 1110 }
\end{aligned}
$$


فمن الممكن توجيه الاستثمار الاجنبي المباشر في مشاريع توليد الطاقة وخاصة المتجددة مثل طاقة الرياح حيث تتمتع مصر بوفرة في مصادر طاقة الرياح في منطقة خليج السويس والتي

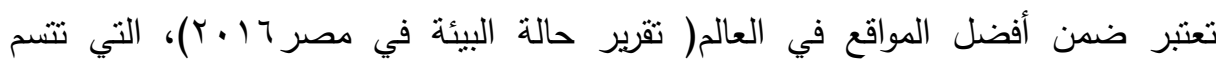
بسرعات رياح عالية ومنتظمة كما تعتبر المساحة الواقعة غرب خليج السويس من المناطق الواعدة لإقامة مشروعات الرياح الكبرى حيث تتوافر فيها مواقع ذات منوسط سرعات رياح

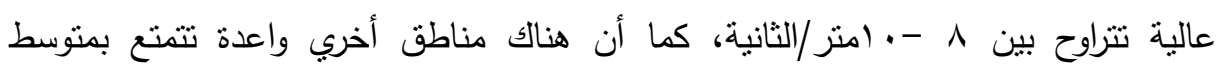
سرعات رياح تتراوح ما بين v-1 متر / الثانية شرق وغرب وادي النيل بمحازاة محافظة بني سويف والمنيا ومنطقة الواحات الخارجة ومحافظة الوادي الجديد ـ كذللك الطاقة الثمسية حيث تقع مصر جغرافيا بين خطى عرض r r و, إ شمالا، وبهذا فإن مصر تعتبر فى قلب الحزام الثمسى العالمى وبذلك فإنها تعد من أغنى دول العالم بالطاقة الثمسية (محمد منير

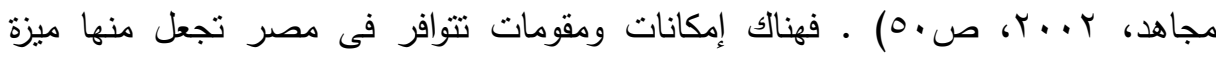
تتافسية لمصر فى مجال الطاقة الثمسية من بين أعلى الحقول الثمسية فى العالم، تتمتع مصر بسطوع شمسى كبير يؤهلها لاستغلال الطاقة الثمسية، حيث تظهر نتائج الأطلس

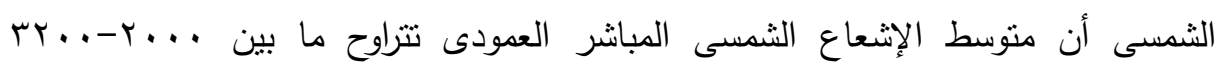
كيلووات.ساعة/م/السنة، نتراوح ساعات السطوع الثمسى بين 9-11 ساعة يوميا مع أيام غياب محدودة على مدار العام، هذا إلى جانب وفرة الأراضي الصحراوية المشمسة أغلب أيام السنة، حيث تمثل مساحة الصحراء فى مصر أكثر من 99\% وتصل درجة الحرارة فى جنوب

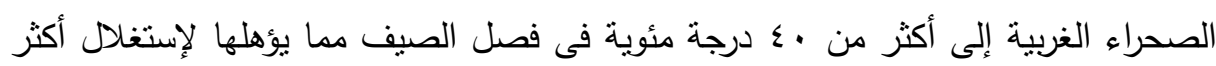

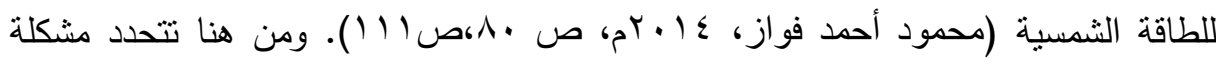
الدراسة في التساؤل التالي ما هو دور الاستثمار الأجنبي المباشر في مجال الطاقة المتجددة

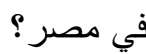

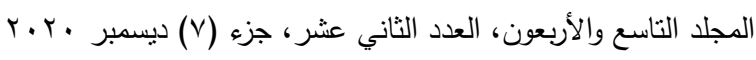

$$
\begin{aligned}
& \text { الترقيم الدولي 0826-1110 }
\end{aligned}
$$




\section{أسهيلا المهيه}

يتمثل السؤال الرئيسى للبحث فى السؤال التالى: ما هو دور الاستثمار الأجنبى المباشر فى مجال الطاقة المتجدة فئى مصرّ؟ والأى يتفرع

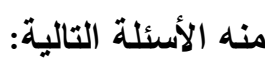

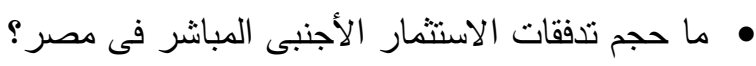

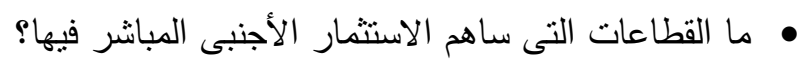

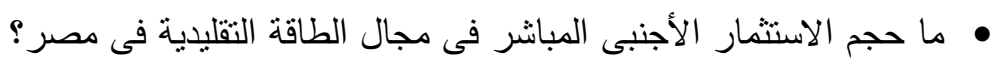

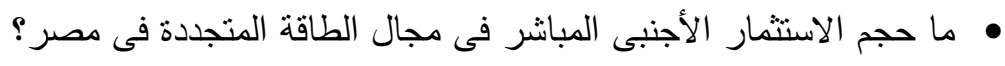

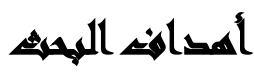

يتمنل الهدف الرئيسى للبحث فى التعرف على دور الاستثمار الأجنبى المباشر فى مجال الطاقة المتجددة فى مصر • والذى بتفرع منه الأهداف الفرعية التالية:

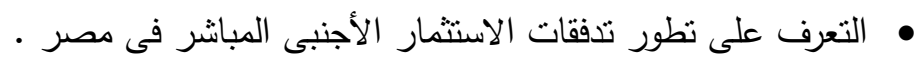

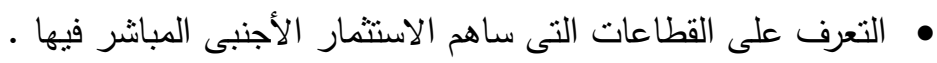

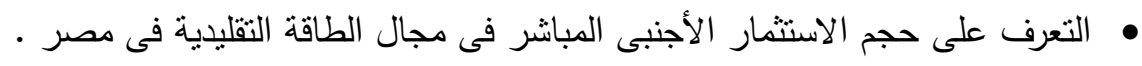

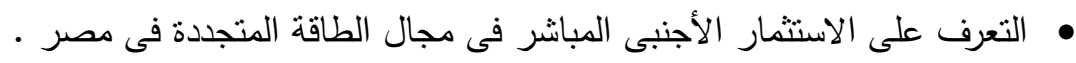

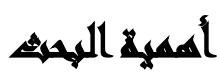

تتطلق أهية هذا البحث من أهية الموضوعات التي ينتاولها فمن ناحية الاستثمار الأجنبي المباشر الذي تتسابق الدول في جذبه للحصول على المزايا العديدة التي يوفرها

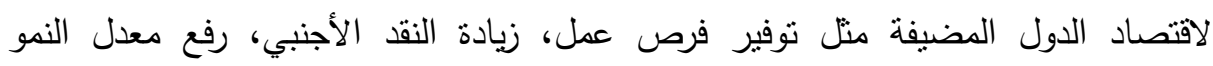

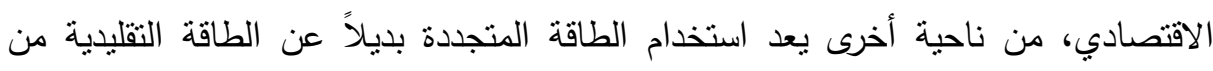
الأهداف الرئيسية للتتمية المستدامة والتي تسعى دول العالم إلي زيادة مساهتمة من انتاج

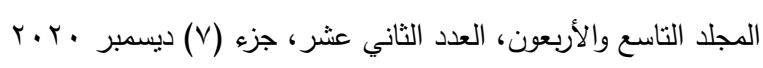

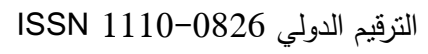


الطاقة الكلي، وتعد مصر من الدول الجاذبة للاستثمار في هذا المجال بسبب الامكانات

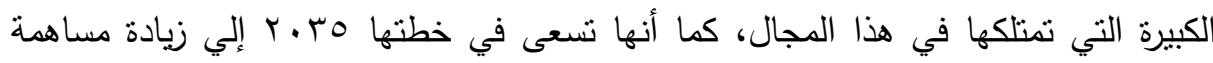

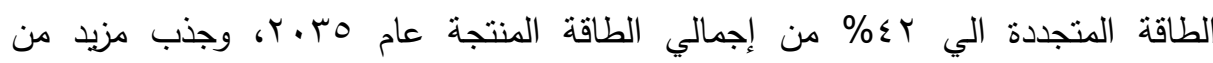

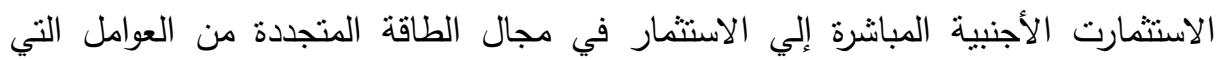
تساعد على تحقيق هذا الهذف.

إن تقييم الوضع الراهن لدور الاستثمار الأجنبي المباشر في مجال الطاقة المتجددة

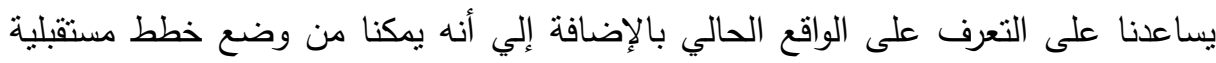

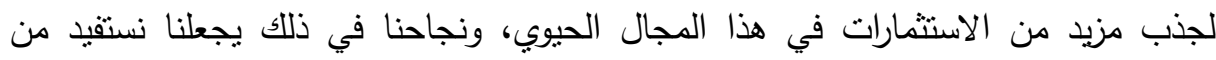

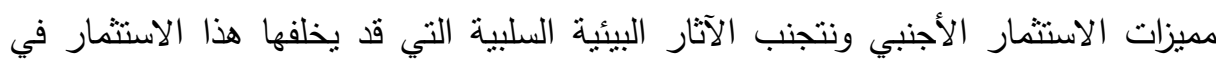
بعض الأحيان بسبب اتجاهه نحو الصناعات الملوثة للبيئة.

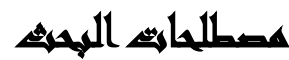

• الاستثمار الأجنبى المباشر : تكوين منشأة أعمال جديدة أو توسيع منشأة قائمة، وذلك

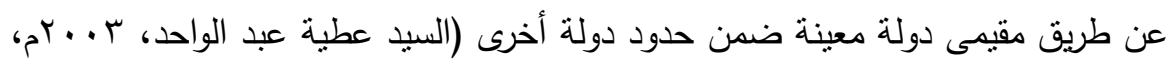
صن • الطاقة المتجددة: هى تلك الطاقات التى تتكرر مصادرها أو وجودها فى الطبيعة على

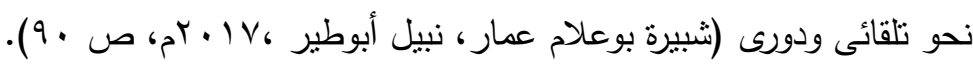

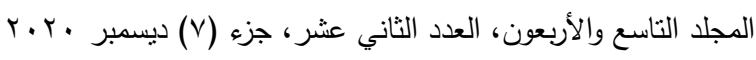

$$
\begin{aligned}
& \text { التزقيم الدولي 0826-0 التوني }
\end{aligned}
$$




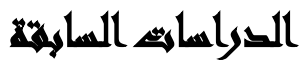

بعد مسح الدراسات السابقة ذات الصلة بموضوع الدراسة توصل الباحثون إلى أن الدراسات التى تتاولت الاستثمار الأجنبى المباشر كانت تدور حول ثلاثة محاور وهى كالتالى: • المحور الأول: تتاول المحور الأول واقع الاستثمار الأجنبى المباشر ومن أمثلة هذا

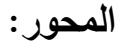

- دراسة أسيدو إليزابيث Asiedu, Elizabeth († (†)، تحت عنوان "الاستثمار الأجنبي المباشر في أفريقيا : دور الموارد الطبيعية، حجم السوق، سياسة الحكومة، عدم وضوح السياسات والمؤسسات" . تهدف الدراسة إلي الإجابة علي ثلاثة أسئلة: ما هي محددات الاستثمار الأجنبي

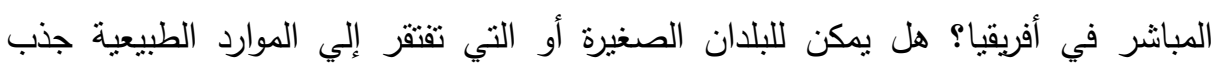

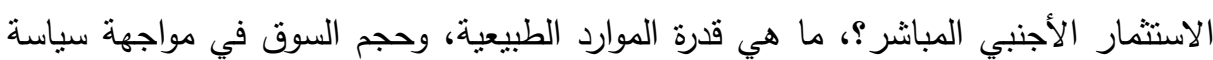

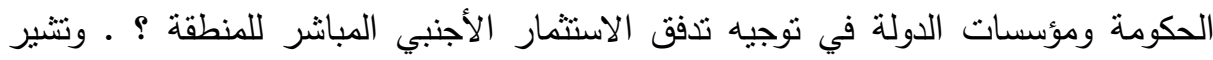
نتائج هذه الدراسة إلي أن الأسواق المحلية الكبري، نوافر الموارد الطبية الطبئية الطية، البنية التحتية

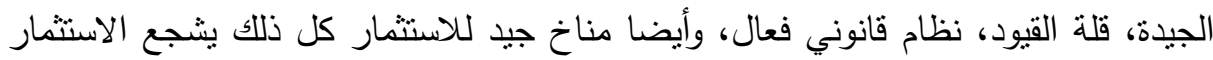
الأجنبي المباشر • وفي المقابل الفساد وعدم الإستقرار السياسي له نأثير عكسي، وهذة النتائج

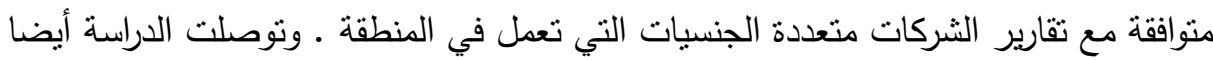

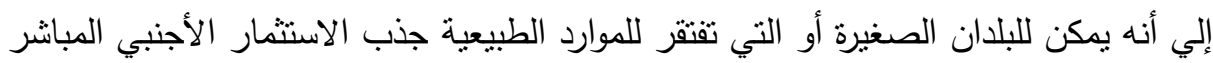

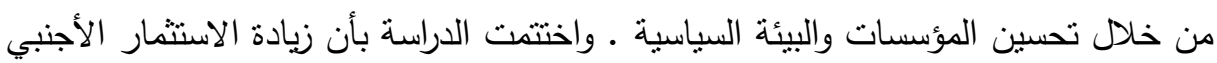

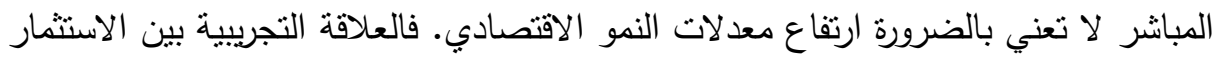
الأجنبي المباثر والنمو غير واضحة، فقد وجدت بعض الدراسات وجود علاقة إيجابية بين

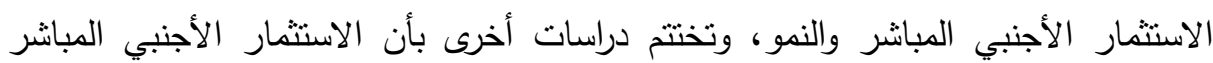

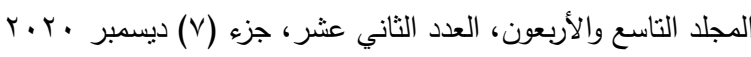

$$
\begin{aligned}
& \text { الترقيم الدولي 0826-1110 }
\end{aligned}
$$


يعزز النمو ولكن بشروط معينة .و من هنا استتتج الباحث أن العلاقة بين الاستثمار الأجنبي

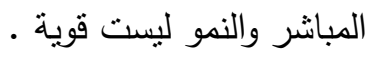

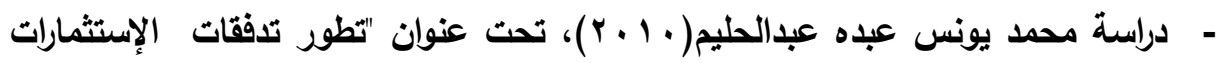
الأجنبية المباشرة في ضوء السياسات والاجراءات التيسيرية للاستثمار والمستثمرين

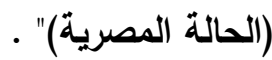

يهدف هذا البحث إلي إبراز الأهمية الاقتصادية والمالية والاجتماعية للإصلاح الاقتصادي، وإيضاح دور السياسة الضريبية في التنمية الاقتصادية، وأيضا إبراز مدي مواكبة الإناء

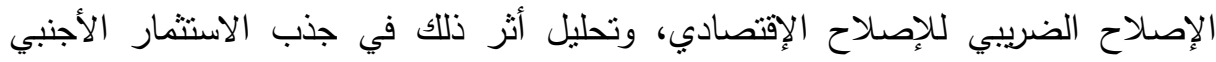
المباشر لوقد اختبر الباحث فرضين الأول أن هناك تأثنير إيجابي لعملية الإصلاح

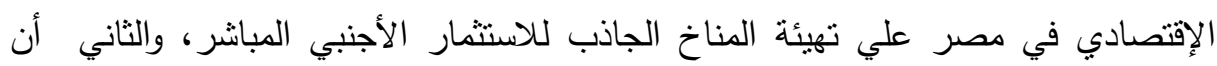

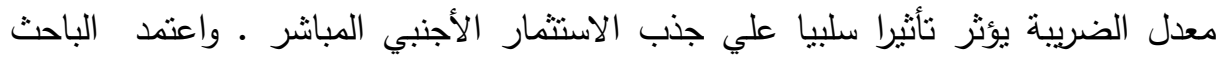

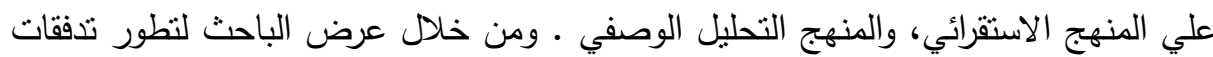
الاستثمارات الأجنبية المباشرة إلي مصر في ضوء ما التبعته مصر من سياسات واجراءات

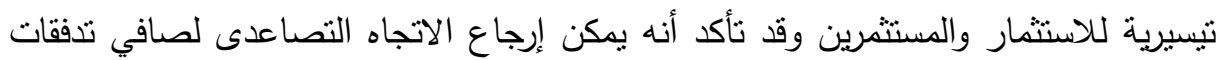

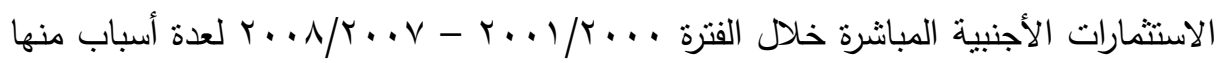
إضفاء المرونة علي الإطار التشريعي الخاص بالاستثمار الأجنبي المباشر، وأيضا تسهيل

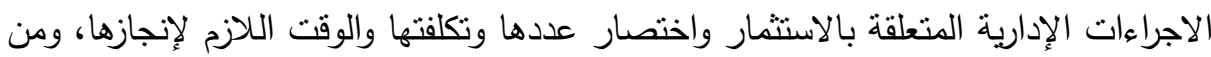
هنا يمكن القول أن هناك علاقة إيجابية مباشرة بين الاجراءات التي اتخذتها الدولة من أجل

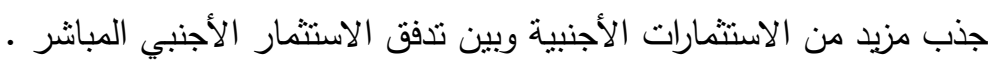

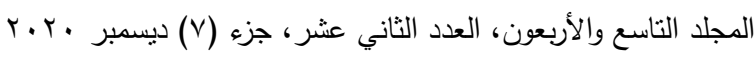

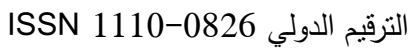


• المحور الثاني: اهتمت دراسات المحور الثانى بلراسة الاستثمار الأجنبى المباشر وعلاقته بالتنمية ومن أمثلة هذا المحور:

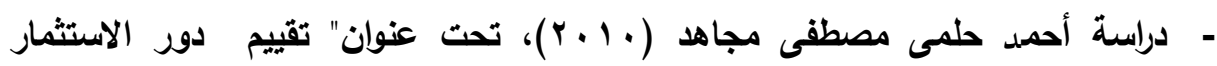

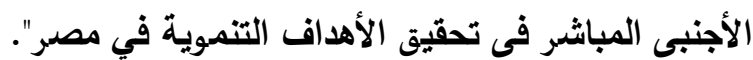

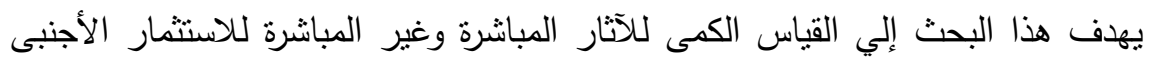

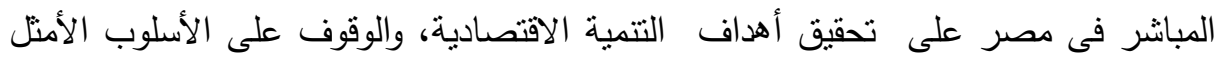

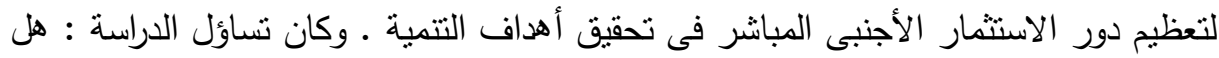

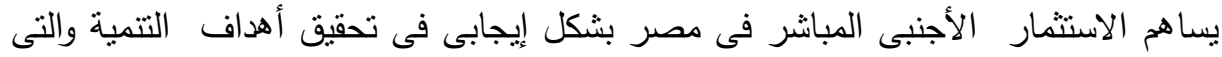

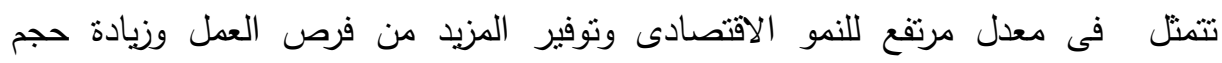

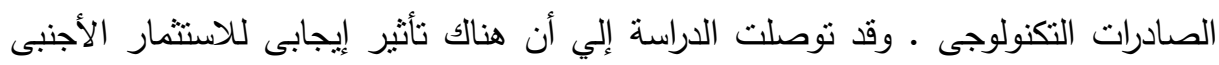

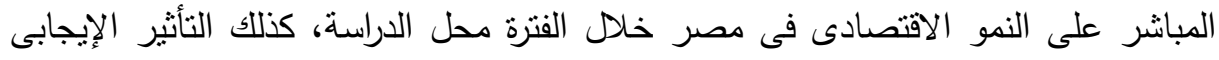

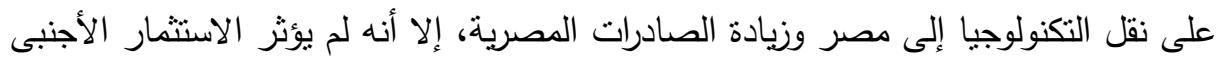

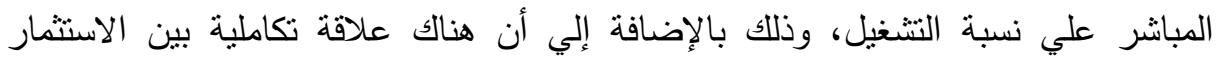

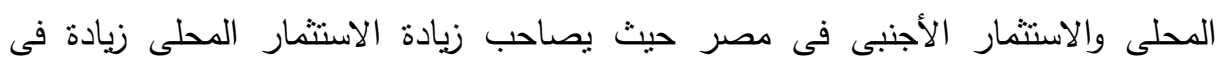

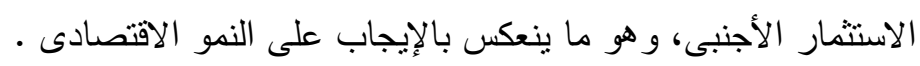

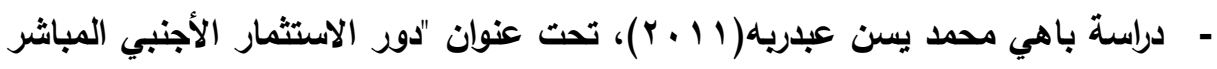

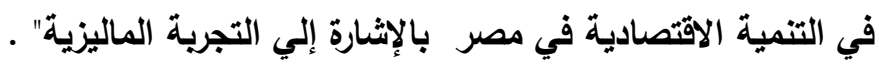

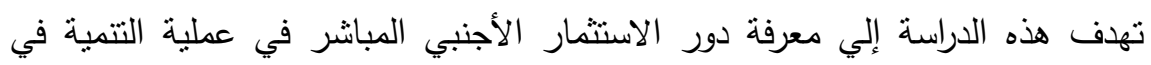

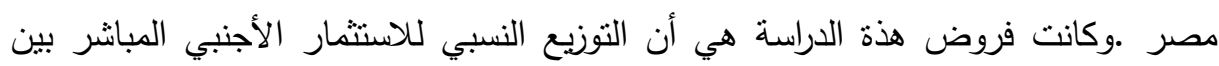

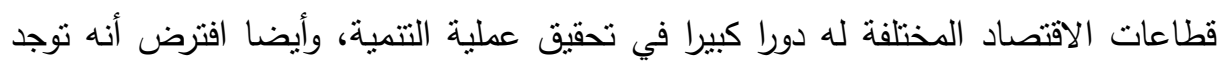
علاقة وطيدة بين حوافز الاستثمار الأجنبي المباشر واعفاءاته وحجم تدفقه وطبيعته ــ واعتمد

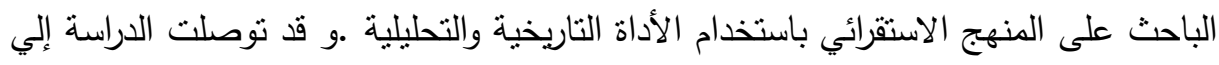

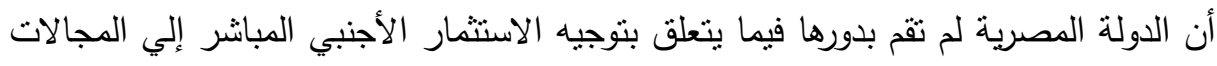

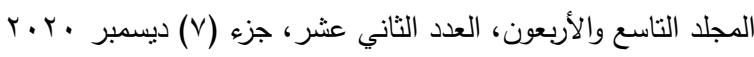

$$
\begin{aligned}
& \text { التزقيم الدولي }
\end{aligned}
$$


التي تخدم عملية التتمية، حيث اهتمت فقط بتقديم مزايا واعفاءات وضمانات عديدة دون أن تربط ذلك بشرط الانجاز التصديري أو باستخدام نسبة معينة من المكونات الداخلية، وأيضا

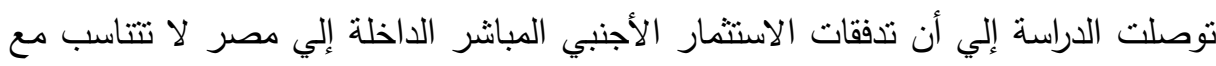

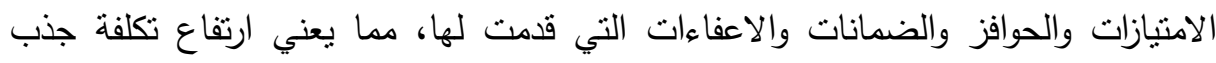
الاستتمار الأجنبي المباشر والمتمثل فيما حصل عليه من إعفاءات وميزات .

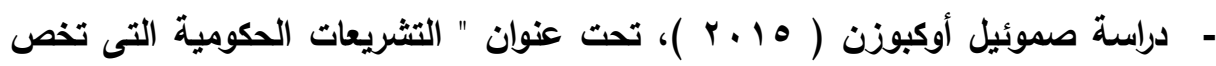

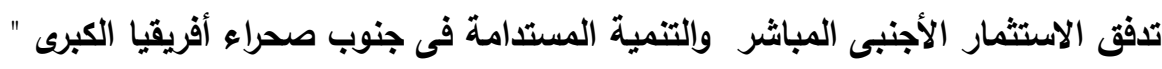

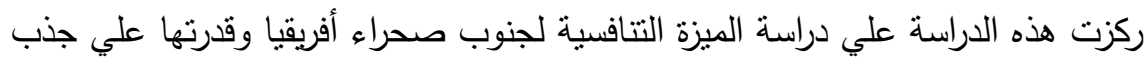
الاستثمار الأجنبي المباشر، وركزت أيضا علي البحث في إمكانية الأنطمة الحكومية الموحدة

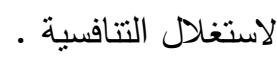
وتوفر هذه الدراسة ثلاثة توصيات متعلقة بالسياسة العامة للاستثمار ، أولا: الحاجة إلى

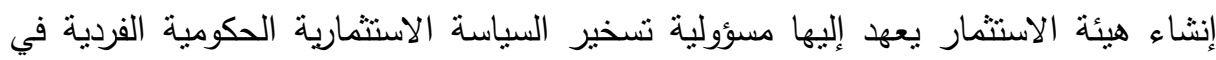
المنطقة، ثانيا: إن الهيئة يجب أن تحدد بوضوح خريطة المناطق الاستثمارية في المنطقة

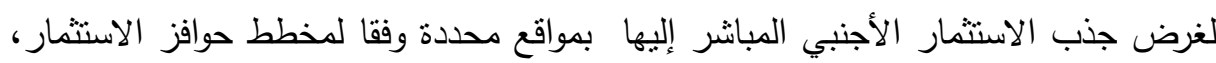
ثالثا: يجب أن يكون هناك اجتماع الاستثمار السنوي لزعماء منطقة جنوب صحراء أفريقيا

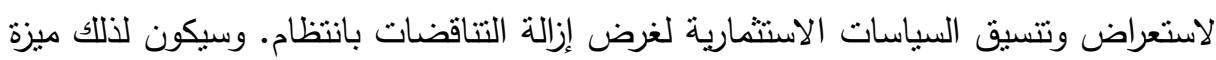

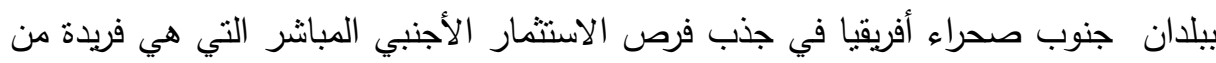
نوعها ولها ميزة تنافسية مطلوبة،مما يؤدي إلي رفع مكانة المنطقة على حد سواء محليا ودوليا باعنبارها سوقا تتافسية للاستثمار الأجنبي المباشر .

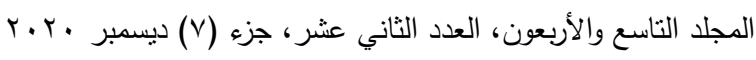

$$
\begin{aligned}
& \text { الترقيم الدولي 0826-1110 }
\end{aligned}
$$


• المحور الثالث: اهتمت دراسات هذا المحور بالبحث فى علاقة الاستثمار الأجنبى

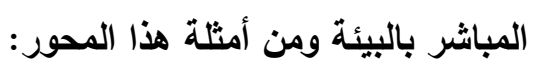

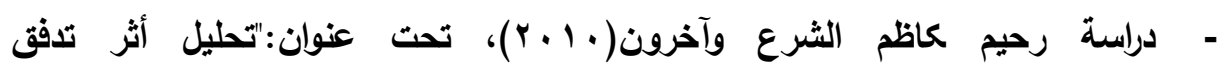
الاستثمارات الأجنبية المباشرة على البيئة ".

تهدف هذه الدراسة إلي تحليل بعض المؤشرات الاقتصادية والبيئية لبلدان مختلفة

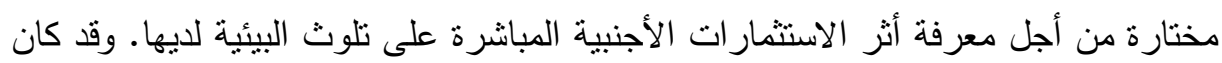

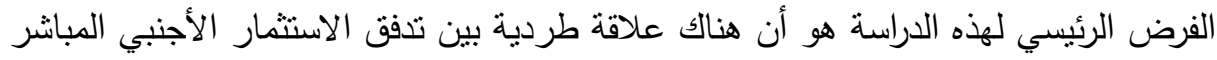

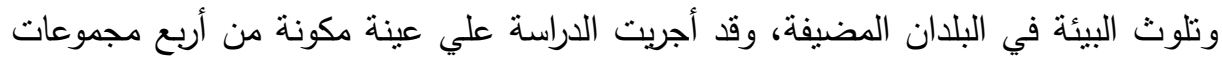
وهي : نموذج البلدان العربية، نموذج المجموعة الأسيوية، مجموعة البلدان الأوربية،

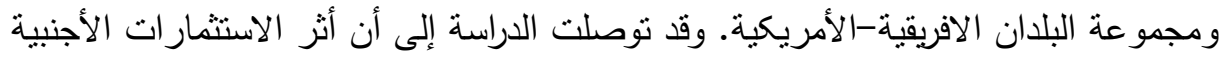

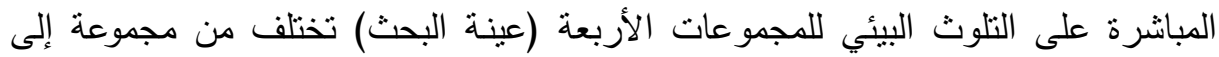
أخرى حسب الإجراءات المنبعة في تلك البلدان، كما نوصلت إلي أن أثز تدفق الإستثمار

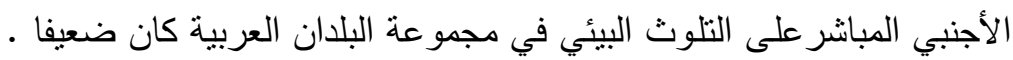

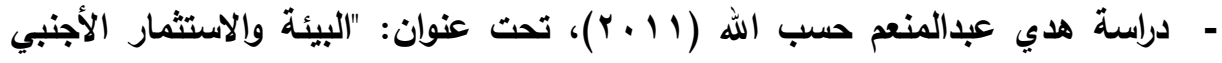

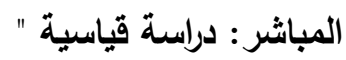

تهدف هذه الدراسة إلي دراسة العلاقة بين الاستثمار الأجنبي المباشر والبيئة من خلال

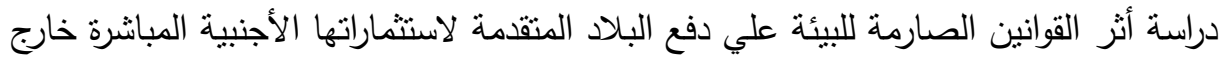
البلاد، كما درست أيضا أثز الاستثمارات الأجنبية المباثرة علي مستوي التلوث في البلاد

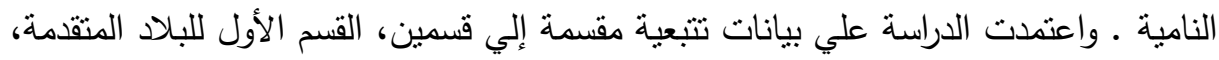

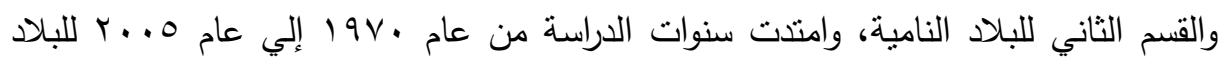

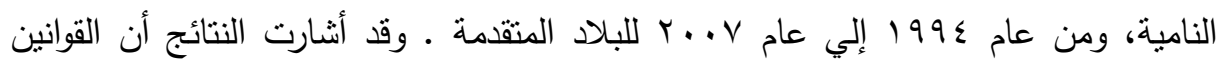

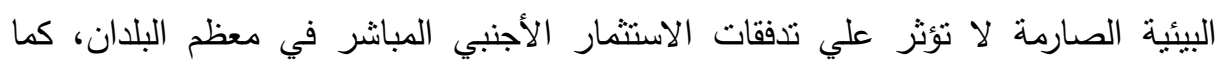

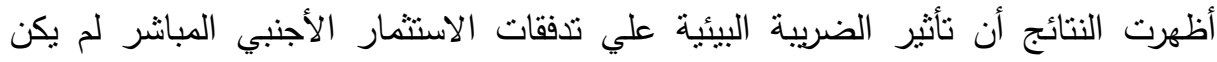

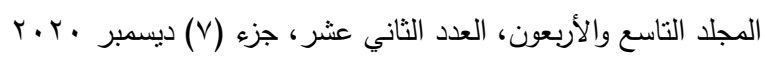


حاسما، وأكدت النتائج أيضا أن في البلدان النامية لا تؤثر تدفقات الاستثمار الأجنبي المباشر

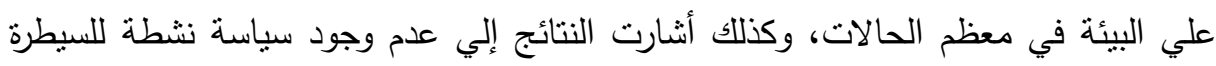

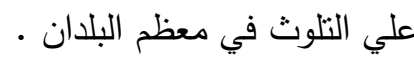
استفاد الباحثون من الدراسات السابقة فى تحديد أهداف البحث بدقة، وفى تحديد مدة

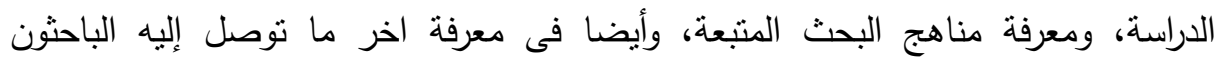
السابقون من نتائج واستخلاص منها بعض المؤشرات وهى كالتنالى : لإنى ل أثارت الدراسات السابقة أن الفساد وعدم الإستقرار السياسي يؤنثر سلبا على تلى تدفق الاستثمار الأجنبى المباشر للاولة المضيفة وهو ما يوضح ما حدث من هروب المستثرين

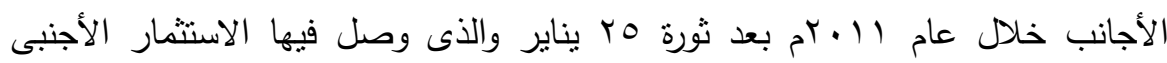

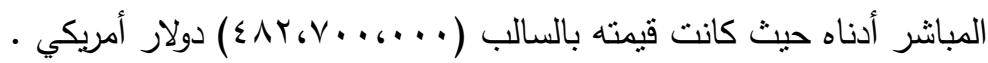

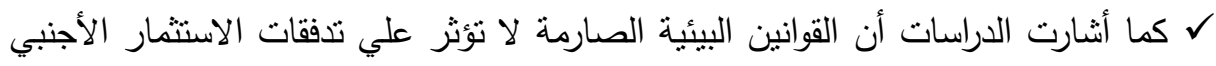

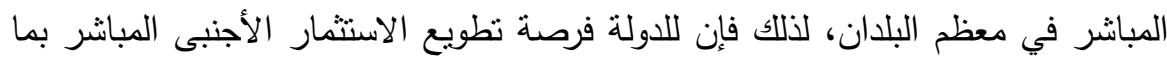
يحقق أهداف التتمية المستدامة للدولة ووضع القوانين البيئية اللازمة للحفاظ على بيئتها

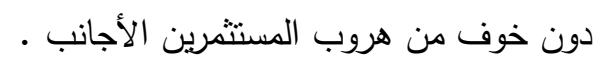
ل أن إضفاء المرونة علي الإطار التشريعي الخاص بالاستتمار الأجنبي المباشر وأيضان

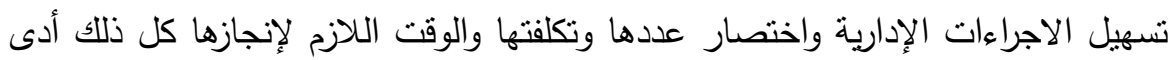

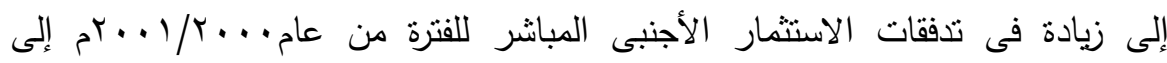

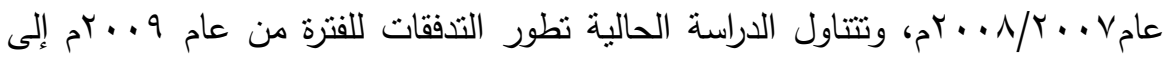

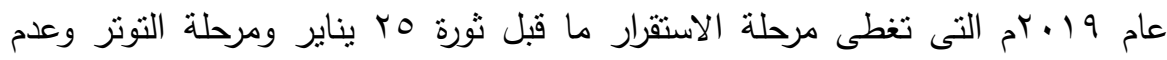
الاستقرار ومرحلة محاولة إعادة الاستقرار • $\checkmark$ أن هناك ثأثير إيجابى للاستثمار الأجنبى المباشر على نقل التكنولوجيا إلى مصر ، لذادرالك

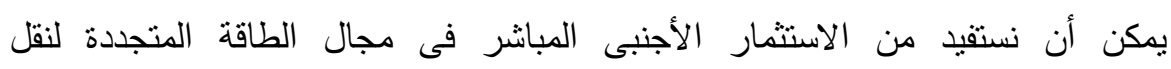

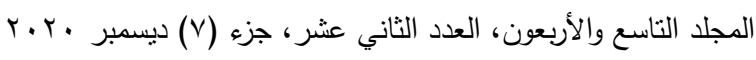

$$
\begin{aligned}
& \text { الترقيم الدولي 0826-1110 }
\end{aligned}
$$


التكنولوجيات الأحدث الخاصة بها لتحقيق الأهداف التتموية المنوط تحقيقها بأقل وقت وجهد وبأفضل جودة ممكنة . و ل ل أوضحت الدراسات أن الدولة المصرية لم تقم بدورها فيما يتعلق بتوجيه الاستثمار الأجنبي

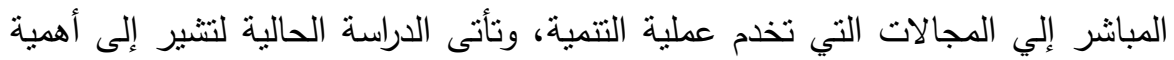
ربط خطط جذب الاستثمار الأجنبى المباشر بمجالات تخدم أهداف التتمية المستدامة

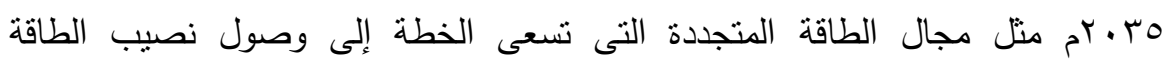

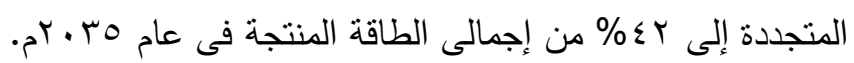

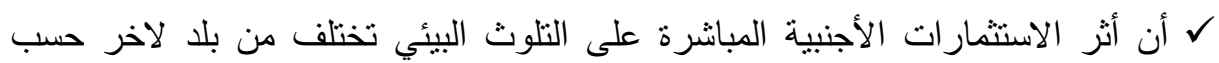
الإجر اءات المتبعة في تلك البلد. ل أوضحت الدراسات السابقة أيضا أن هناك علاقة تكاملية بين الاستتمار الدحلى والاستثمار الأجنبى فى مصر حيث يصاحب زيادة الاستثمار المحلى زيادة فى الاستثمار الأجنبى.

\section{الإلطار اللنظليه}

أولا: الاستثمار الأجنبى المباشر:

تعنبر الاستثمارات الأجنبية المباشرة من أهم الصور تعبيرا عن اقتصاديات المشاركة

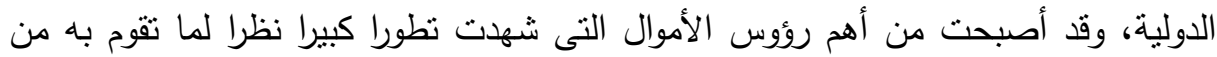
دعم نمو اقتصادات الدول المضيفة من خلال إدخال التقنيات المنقدمة والمهارات التتظيمية والإدارية كما تعمل على تحسين الكفاءة الاقتصادية من خلال درجة التنافسية ودعم قدراتها

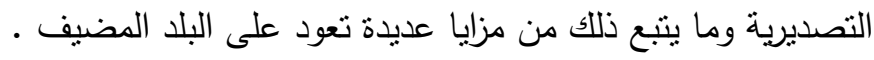

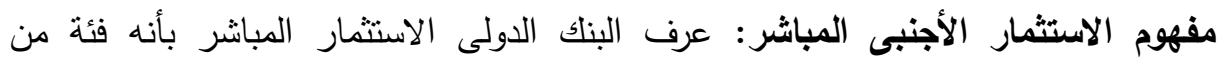

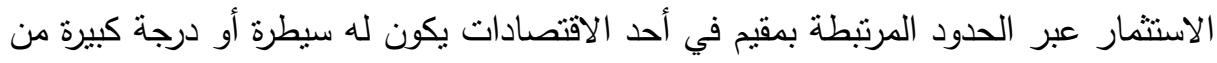

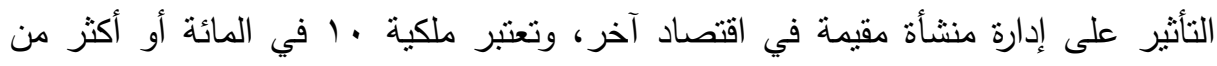

$$
\begin{aligned}
& \text { r.r. المجلد الثاسع والأربعون، العدد الثاني عثر، جزء (V) ديسمبر } \\
& \text { التزقيم الدولي }
\end{aligned}
$$


الأسهم العادية أو أسهم التصويت هي المعيار لتحديد وجود علاقة استثمار مباشر(الموقع

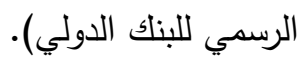

وتعرف أيضا الاستثمارات الأجنبية المباشرة بأنها "استثمارات تتم خارج بلد المستثمر

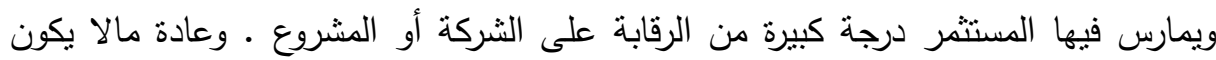

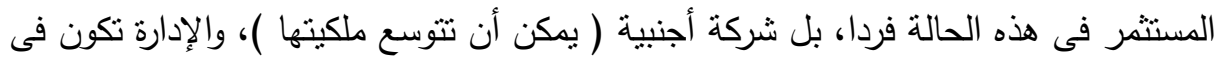

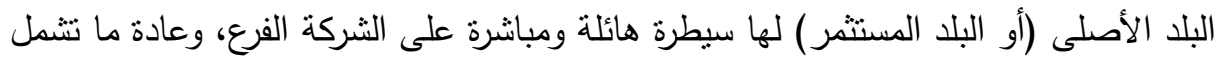

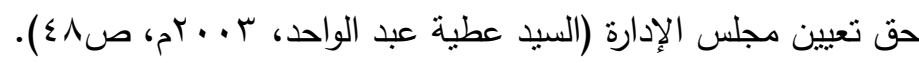

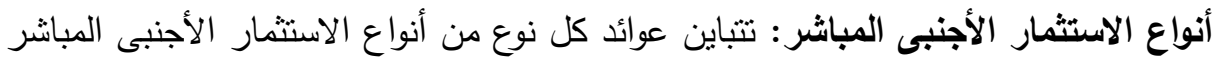

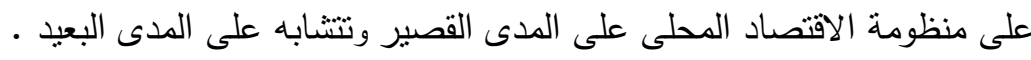
1-أنواع الاستثمار الأجنبى المباشر من حيث الملكية : • الاستثمر المشترك: هو مشروع يمتلكه أو يشارك فيه طرفان أو أكثر من دولتين مختلفتين بصفة دائمة، والمشاركة هنا لا تقتصر على وحدة رأس المال بل تمتد إلى الإدارة والخبرة والعلامات التجارية وبراءات الإختراع ... الخ، ويتم هذا الاستثمار المشترك بنسب متفاوتة

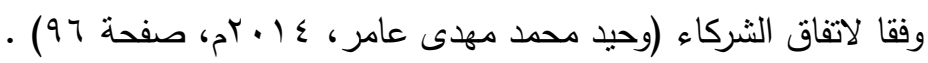
• الاستثمارات المعلوكة بإكامل للمستثمر الأجنيف: تتمثل هذة المشروعات فى قيام الثركات متعددة الجنسيات بإنشاء فروع للإنتاج أو التسويق أو أى نوع أخر من أنواع

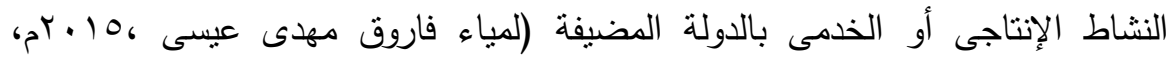

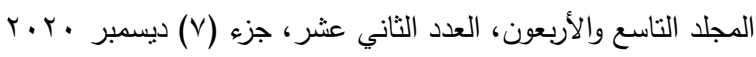

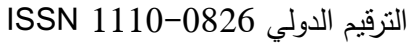




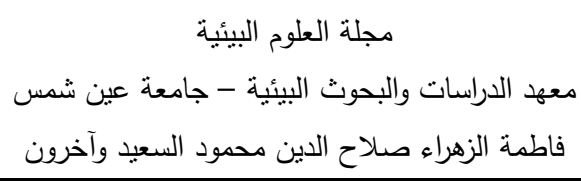

r- أنواع الاستثمار الأجنبى المباشر وفقا لكيفية دخوله للسوق المحلى (فايز عبد الهادى

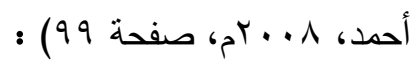

الثركات الجديدة: حيث تقوم شركة أجنبية بالاستثمار فى السوق المحلى عن طريق افتتاح

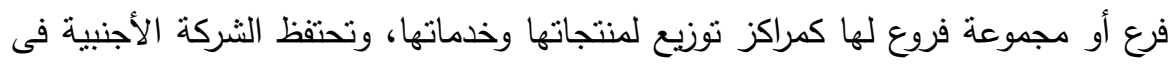
مثل هذا النوع من الثركات بحق الإدارة والتشغيل والتسويق وجميع الأنشطة الأخرى الداخلة ضمن نطاق تحقيق أهدافها الاقتصادية. • شركات الاستحواذ: حيث تقوم شركة أجنبية بالاستثمار فى السوق المحلى عن طريق شراء الهاء نسبة من أسهم شركة محلية قائمة كافية لإدارتها، وتطوير استراتيجياتها المقبلة .

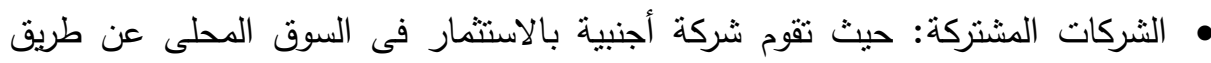
مشاركة مستثر أو مجموعة مستثرين فى تأسيس شركة جديدة ضمن منظومة الاقتصاد

\section{r-أنواع الاستثمار الأجنبى المباشر من حيث الهيد منهيا:}

هالاستثمار الباحث عن المولد ( الثرولت الطبعية ): يسعى هذا النوع من أنواع الاستثمار

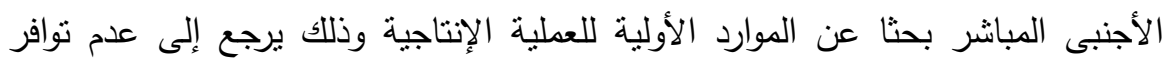

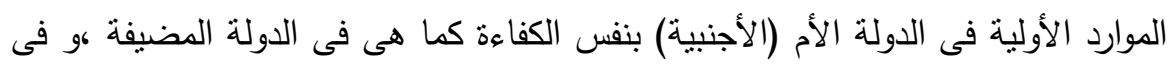

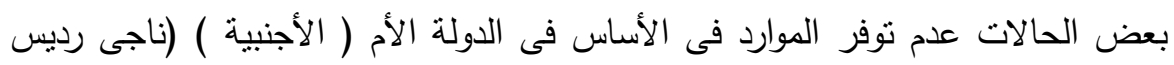

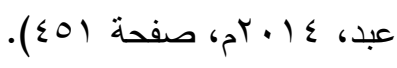

• الاستثمار الباحث عن كفاعة الأداء : هى استثمارات تبحث عن الربحية العالية من خلال

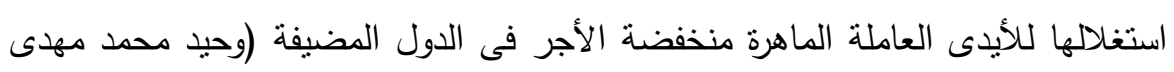

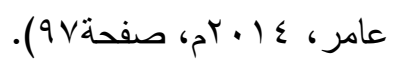

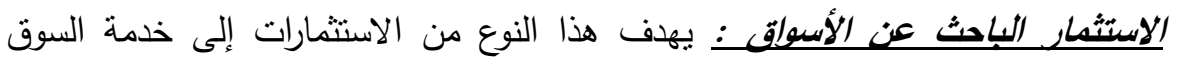

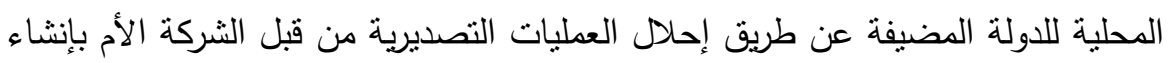

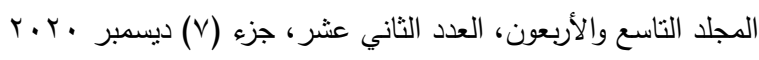

$$
\begin{aligned}
& \text { الترقيم الدولي 0826- ISSN 1110 }
\end{aligned}
$$


وحدات إنتاجية تابعة الدولة المضيفة لإنتاج السلع نفسها والخدمات التى تتنج فى المقر

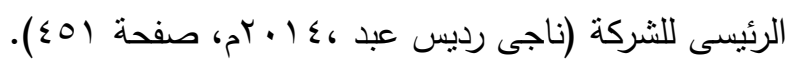

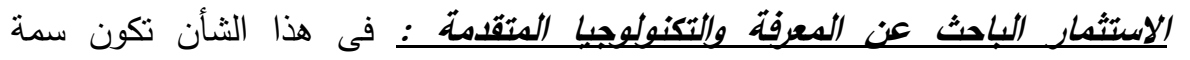
اتجاهات تحركات رأس المال عن طريق مشروعات الاستثمار الأجنبى تجاه الدول

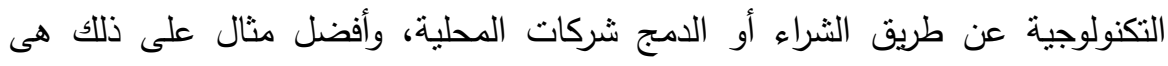
الاستثمارات الأمريكية والألمانية داخل المؤسسات اليابانية وذلك للاستفادة من التكنولوجيا

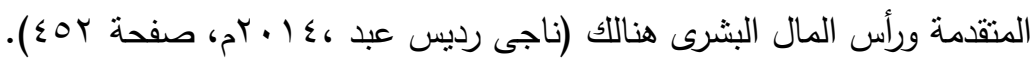

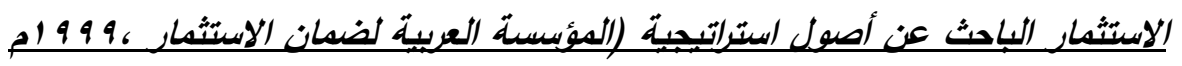
كصفحة r): تقوم الثركة بالاستثمار فى مجال البحوث والتطوير فى إحدى الدول النامية أو المنقدمة مدفوعة برغبتها فى تعظيم الربحية .

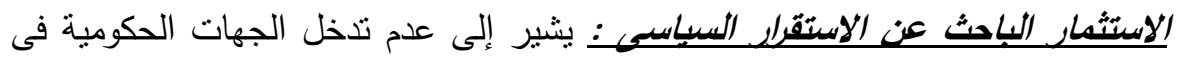
عمل المشروعات الاستثمارية الأجنبية بجانب مجموعة من العوامل الأخرى منل الثفافية

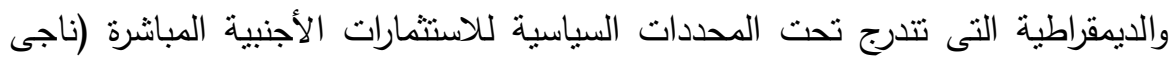

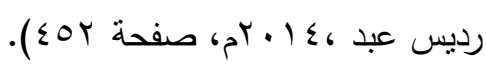

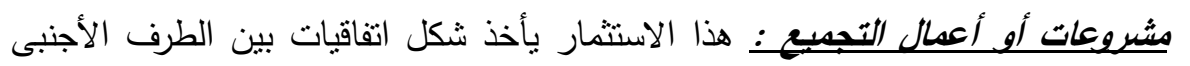

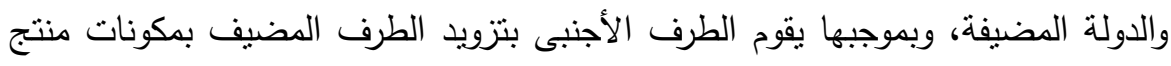
معين ليجمعه وإخراجه فى شكل منتج نهائى (وحيد محمد مهدى عامر ، ـ ا بام، صفحة

• الاستثمر فحى المناطق العرة : فى داخل المنطقة الحرة يسمح بإقامة المشاريع الخاصة برؤوس الأموال الأجنبية أو الوطنية أو المشتركة ويتم فيها تداول البضائع المحلية والخارجية وتجرى عليها بعض العمليات الصناعية ولا تدفع رسوم جمركية على تللك البضائع إلا عند اجنيازها حدود المنطقة الحرة إلى داخل الدولة ( أنور عبد الخالق، محمد ولثد عباس، 9V^ (م، صفحة 9V). ويهدف انثاء المناطق الحرة إلى تشجيع اقامة الصناعات 540

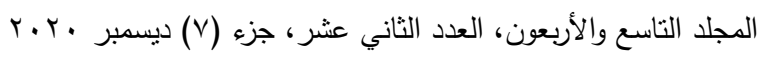

$$
\begin{aligned}
& \text { التزقيم الدولي 0826-1110 التاني }
\end{aligned}
$$


التصديرية، ولأجل هذا الغرض تسعى الدول لجعل المناطق الحرة جاذبة للاستثمارات وذلك

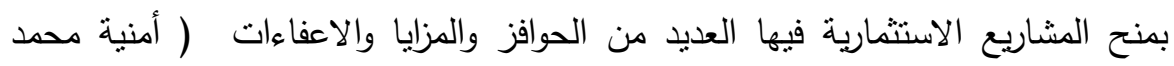

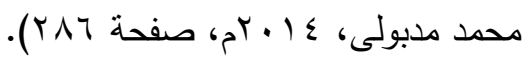

$$
\begin{aligned}
& \text { مزايا الاستثمار الأجنبى المباشر: }
\end{aligned}
$$

\section{1-مزايا الاستثمار الأجنبى المباشر بالنسبة للاولية المضيفة :}

يعد الاستثمار الأجنبى المباشر وسيلة أكثر أمانا لتمويل الخطة الاستثمارية مقارنة بالقروض باعنباره غير منشئ للمديونية ولا بولد التزامات (عبدالفتاح محمد عبدالفتاح،

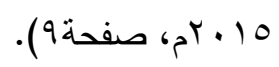

الاستخدام الأمتل لموارد الدولة المضيفة، حيث أن الاستثمار الأجنبى بطبيعته استثمار

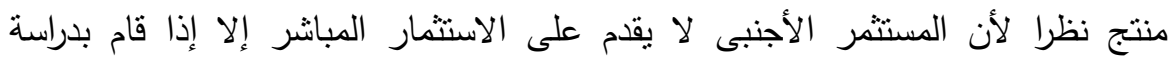

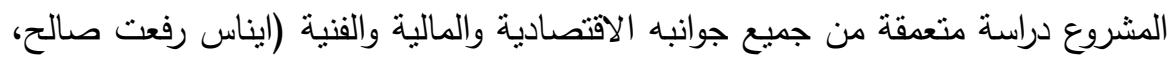

$$
\text { ( )... }
$$

تمتاز مشروعات الاستثمار الأجنبى المباشر بقدرة عالية على تعيين ومكافئة العمال طبقا

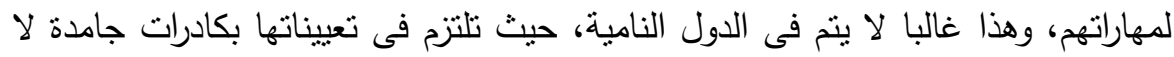

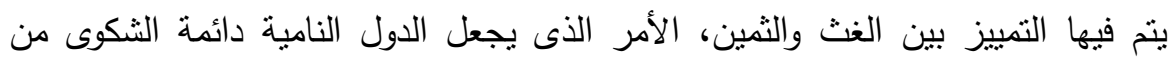

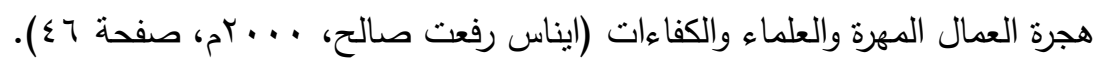
المساهمة فى التكوين الرأسمالى، حيث تكون هذة المساهمة إيجابية عندما يكون حجم التدفقات الرأسمالية الداخلة للدولة المضيفة للاستثمار أكبر من حجم التدفقات الرأسمالية

$$
\text { الخارجة (خالد عبدالرحمن البسام ،9 · . rم، صفحة ^). }
$$

يؤدى قيام المشروعات الأجنبية المباشرة فى الدول النامية إلى نوفير السلع الإستهلاكية المرتفعة الجودة بأسعار أقل نسبيا، الأمر الذى يؤدى إلى زيادة الرفاهية الاجتماعية، كما

$$
\begin{aligned}
& \text { r.r. المجلد الثاسع والأربعون، العدد الثاني عثر، جزء (V) ديسمبر } \\
& \text { التزقيم الدولي }
\end{aligned}
$$


قد تؤدى هذة السلع إلى الإرتقاء بأذواق المستهلكين وتطوير أنماطهم الاستهلاكية (ايناس

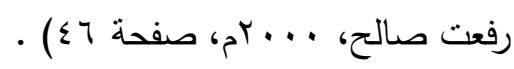
• إقامة علاقات علمية بين فروع الثركات الأجنبية وبين المراكز المحلية للبحث العلمى والتطوير، مما يؤدى إلى اكتساب تلك المراكز لأحدث ما توصلت إليه الثركات العالمية من تكنولوجيا وأساليب بحثية (اوراق بنك مصر البحثيةV999 1). قد يؤدى قيام المشروع الأجنبى إلى تخفيض التكلفة لمشروعات محلية نتيجة نوفير بعض رض

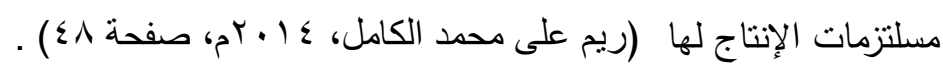
تدريب العمالة المحلية التى تتاح لها فرص العمل بفروع الثركات الأجنبية وإكسابها المهارات التكنولوجية الحديثة، ويقوم العاملون بهذة الفروع بنقل واستخدام مهاراتهم ومعرفتهم العلمية والفنية والإدارية إلى الثركات الوطنية عندما يلتحقون بالعمل بها (عمر

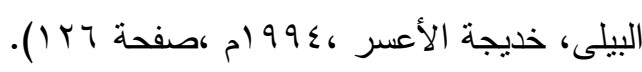
المساهمة فى خفض حدة البطالة بما توفره من فرص عمل لمواطنى الدولة المضيفة بطرق

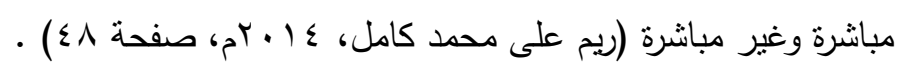
قا يؤدى المستثمر الأجنبى بما لديه من خبرة إعلانية وتسويقية واتصالات مسبقة بالأسواق العالمية إلى نوسيع نطاق السوق المحلية وفتح أسواق جديدة أمام المنتجات المحلية (ريم

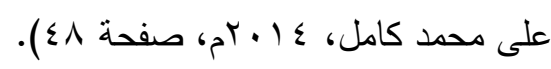
• يؤثر الاستثمار الأجنبى المباشر على ميزان الدفوعات من خلال تدفق رؤوس الأموال الأجنبية مما يجعله مصدرا جيدا للحصول على العملات وزيادة رأس المال المادى فى لى لهى الدولة المضيفة(خالد عبدالرحمن البسام ،9 . . ب م، صفحة 9).

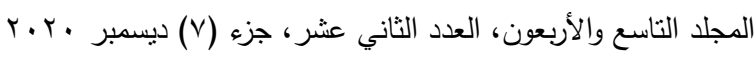

$$
\begin{aligned}
& \text { الترقيم الدولي 0826-1110 }
\end{aligned}
$$


ب - مزايا الاستثمار الأجنيح المباشر بالنسبة للمستثمر الأجنبـ(نادية العلمى شبانة

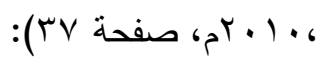

الحصول على المواد الخام من الدول المستثمر فيها والتى لم يكونوا سيجدونها فى بلادهم

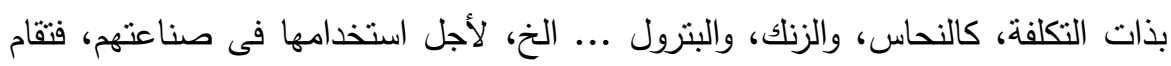

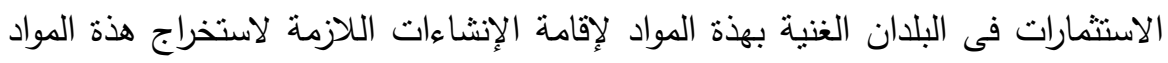

الاستفادة من وفورات الحجم على مستوى الإنتاج فى بعض صناعات الصلب والكيماويات التى من الممكن أن تحقق وفورات كبيرة للحجم ومهمة إلى درجة تجعل مستوى المردودية

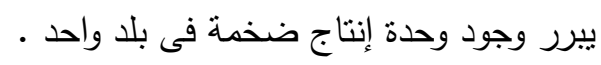

إيجاد أسواق جديدة لمنتجات وبضائع الشركات الأجنبية خاصة لنسويق فائض كبير واهن صن

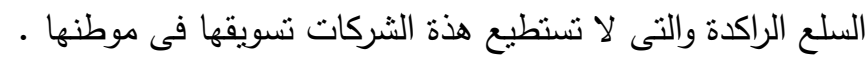

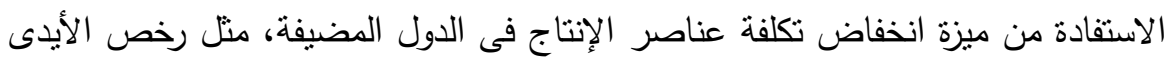

تقليل المخاطر التى تتعرض لها استتمارات الشركات الأجنبية والتى يحملها الإنتاج فى بلد

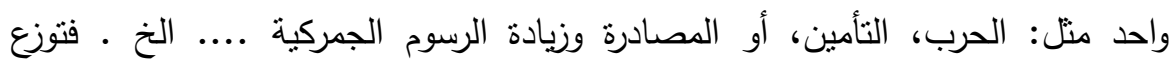
وانتشار الاستثمارات على عدد أكبر من الدول يعمل على تحجيم تلك المخاطر للحد

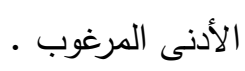

الاستفادة من قوانين تشجيع الاستثمار والإعفاءات الضريبية التى تمنحها كثير من الدول

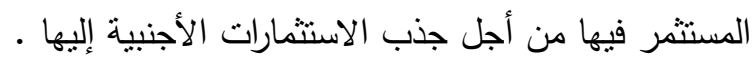

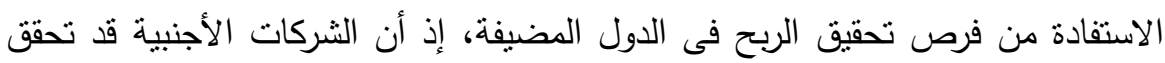

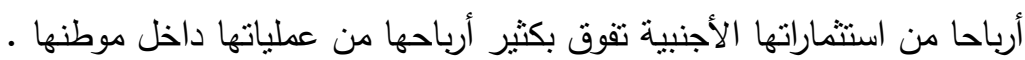

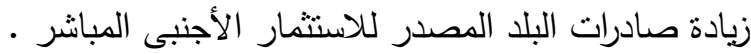

$$
\begin{aligned}
& \text { r.r. المجلد التاسع والأربعون، العدد الثاني عشر، جزء (V) ديسمبر } \\
& \text { التزقيم الدولي 0826-1110 }
\end{aligned}
$$


رغبة المستثر الأجنبى المباشر فى إمكانية فرض السيطرة الاقتصادية والسياسية على البلا المستورد لهذا الاستثمار، فكثيرا ما يتركز هذا النوع من الاستثمار فى قطاعات الاتيه اقتصادية أساسية بالنسبة للبلد المستورد .

ثانياً: الطاقة المتجددة:

مفهوم الطاقة المتجددة: تعرف الطاقة المتجددة بأنها هى الطاقة المستمدة من الموارد

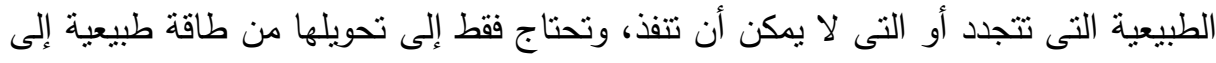

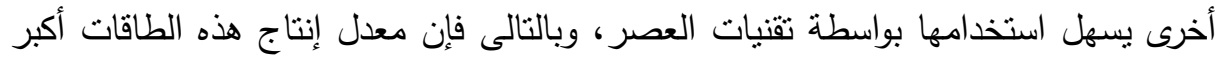

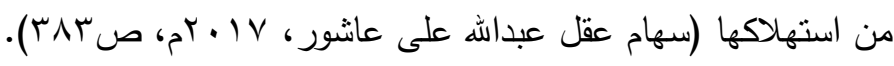

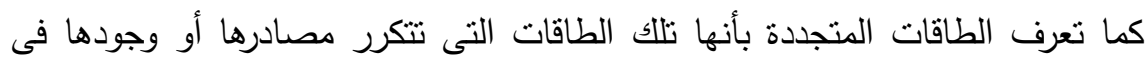

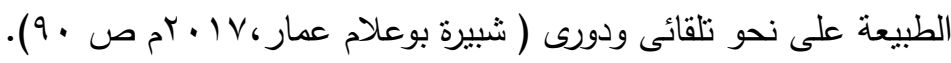

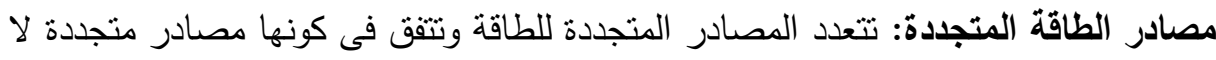
تتضب، وأيضا فى كونها أقل أو عديمة التلوث بالمقارنة مع المصادر الناضبة، ولكن تختلف هونه

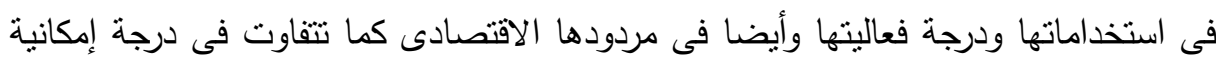

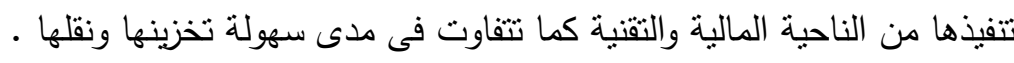

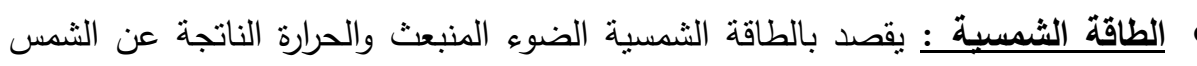
اللذان قام الإنسان بالاستفادة منهما منذ العصور القديمة باستخدام مجموعة من وسائل

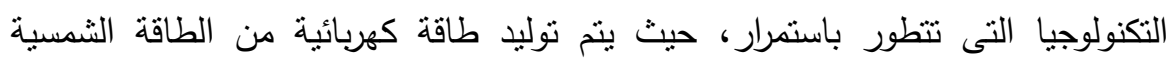

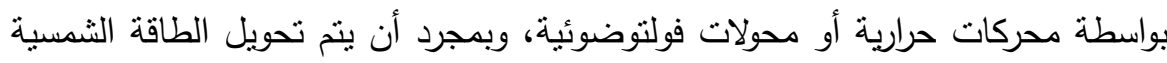
إلى طاقة كهربائية فإن براعة الإنسان هى التى تقوم بالتحكم فى استخداماتها (إياد بن على

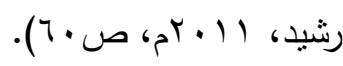
طاقة الرياح : تعتبر طاقة الرياح الأكثر شيوعا لإنتاج الكهرباء فى المنطقة العربية

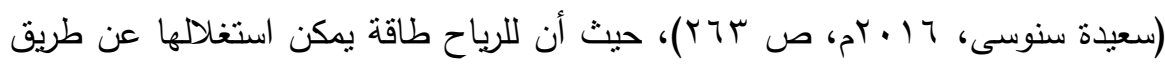

$$
\begin{aligned}
& \text { r.r. المجلد التاسع والأربعون، العدد الثاني عشر ، جزء (V) ديسمبر } \\
& \text { الترقيم الدولي 0826-1110 }
\end{aligned}
$$




\section{مجلة العلوم البيئية \\ معهد الدراسات والبحوث البيئية - جامعة عين شمس للئس \\ فاطمة الزهراء صلاح الدين محمود السعيد وآخرون}

توربينات خاصة ذات ريش دوارة تحمل على عمود ومولد يعمل على تحويل الطاقة

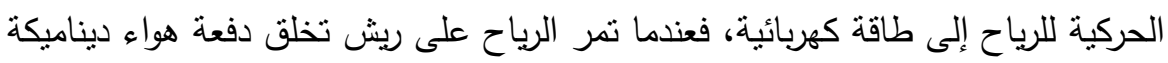

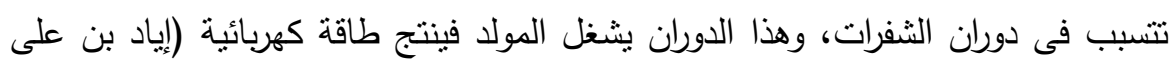

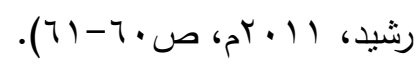

الطاقة المائية: تحتوى المياه المتحركة على مخزون ضخم من الطاقة الطبيعية سواء كانت المياه جزءا من نهر جار أو أمواجا فى المحيط يمكن اعتبارها موردا للطاقة طبيعيا

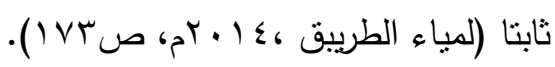

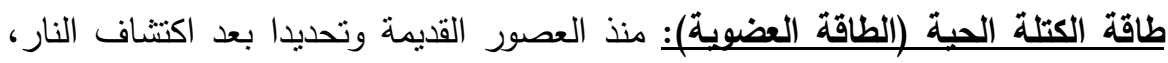
استغل الانسان الأخشاب وبقايا النباتات فى طهى طعامه، فاحتراق الخشب إذن يفضى إلى إنتاج طاقة الكتلة الحيوية، وكذللك استعمال بعض المحاصيل الزراعية كوقود، حيث

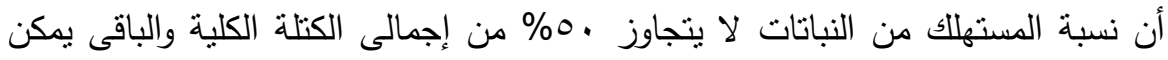
استغلاله فى إنتاج الطاقة، وقد نجح العلماء بالفعل فى إيجاد طرق يمكن من خلالها

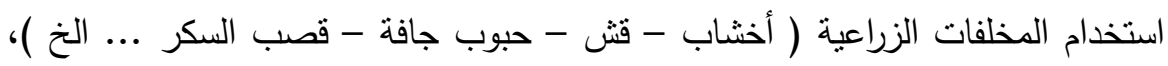
ومخلفات حيوانية (فضلات - جيف)، مخلفات بشرية (فضلات) كمصدر لتوليد الطاقة

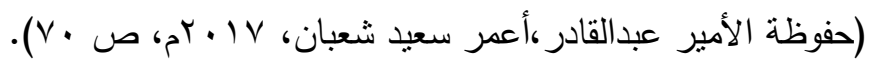
طاقة حلرة باطن الأرض (الحراة الجوفية )؛ يقصد بطاقة حرارة باطن الأرض بأنها

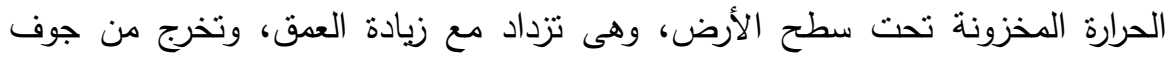

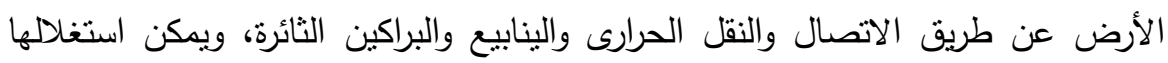
بالطرق الفنية المتوفرة بصورة اقتصادية، ويتجسد هذا النوع من الحرارة فى الماء الساخن ولني والبخار الرطب والجاف والصخور الساخنة والحرارة المضغوطة فى باطن الأرض وأفضلها

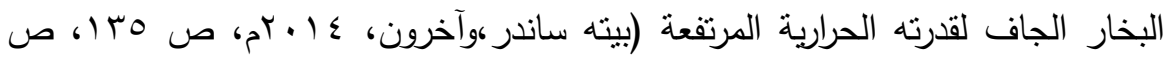

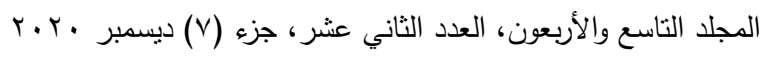

$$
\begin{aligned}
& \text { الترقيم الدولي 0826- ISSN 1110 }
\end{aligned}
$$


طاقة المد والجزي: يقصد بطاقة المد والجزر أنه نظرا لحركة الأرض حول نفسها مرة كل

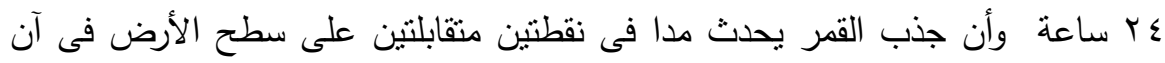
واحد فإن الفترة الزمنية بين كل مدين منتاليين هى باعه إساعة، وفى بعض الخلجان يصل ارتفاع الماء إلى أكثر من · r مترا، وتعد هذه الظاهرة مصدرا جيدا لتوليد الطاقة الكهربائية

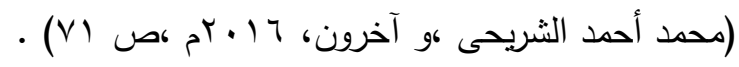

أهمية الطاقة المتجددة:

• ضمان مصدر مستمر ومتجدد للطاقة لتلبية الطلب المتزايد عليها، حيث نتير التوقعات

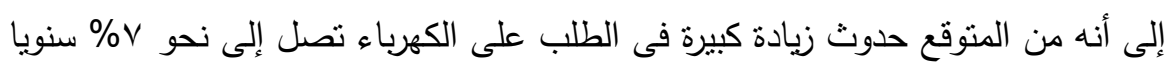

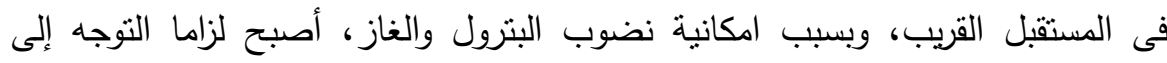

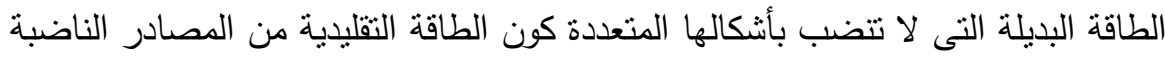

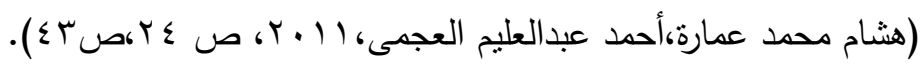

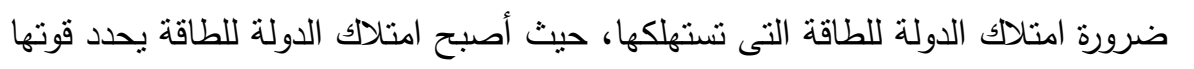

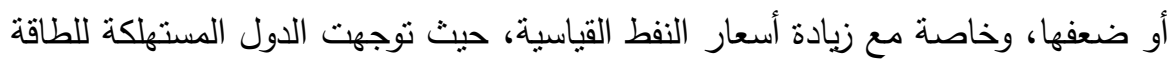
وحتى المنتجة لها إلى تطويرمصادر طاقة بديلة، واجتمعت كلها على ضرورة اسخدام الطاقات المتجددة، بما أ ننا سنجبر فى يوم ما على استخدامها لأنها ستكون المصدر

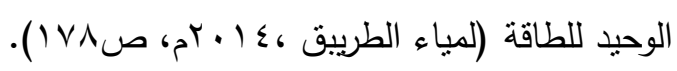

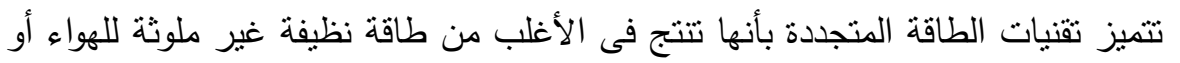

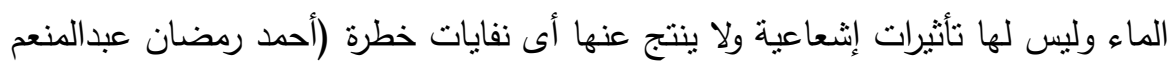

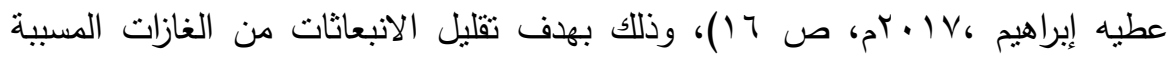
لللتوث البيئى المسببة للإحتباس الحرارى الناتجة من استخدام مصادر الطاقة الأحفورية

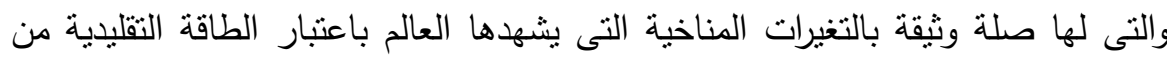

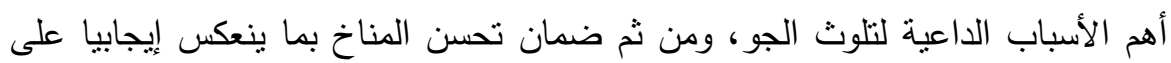

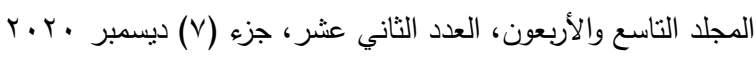

$$
\begin{aligned}
& \text { الترقيم الدولي 0826-1110 }
\end{aligned}
$$


النشاط الاقتصادى وعلى صحة الإنسان (هشام محمد عمارة،أحمد عبدالعليم

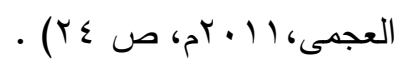

تتنكل الطاقة المتجددة إحدى وسائل حماية البيئة، فقد أصبح الاهتمام بالبيئة اهتماما

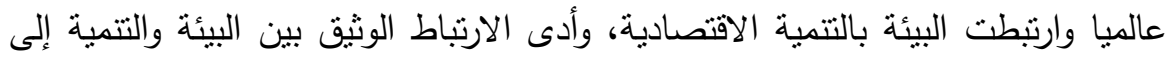

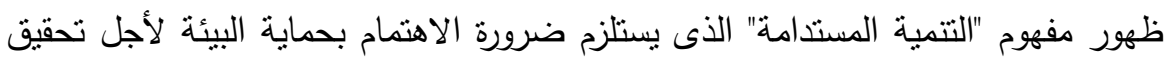

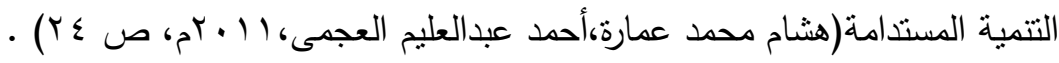

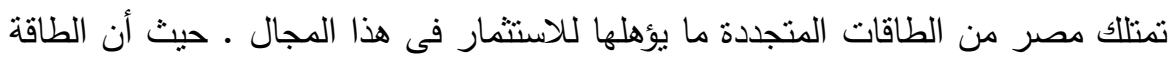
لها كل مقومات وخصائص الصناعات الأخرى، وهذا يساعد على إنشاء المشاريع وإقامة

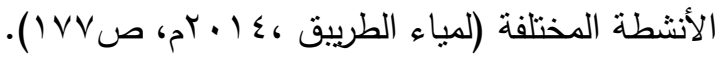
الاستعمال اللامركزى لهذه الطاقة يجعلها توفر مصاريف النقل على المستهلك (لمياء

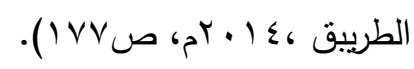
الاعتماد على مصادر متجددة للطاقة يخفف الضغط على المستخدم من النفط والغاز فى الثى

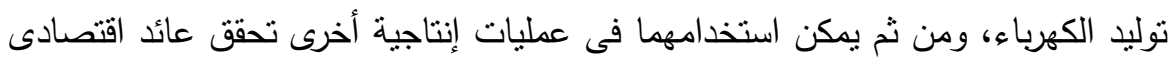
أكبر، بالإضافة إلى توفير كميات أكبر منها تصبح متاحة لزيادة الصادرات (هثام محمد

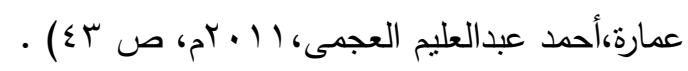
هؤثز مدى وجود الطاقة وتكلفة الحصول عليها فى استراتيجية التصنيع والتوطين الصناعى، فالطاقة تعتبر موجهه للتتمية فى حدود معينة، فهى تلعب دورها التوجيهى

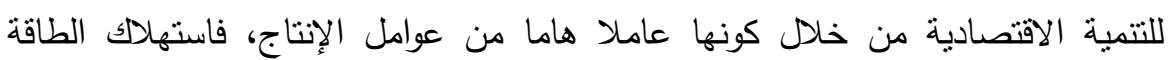
ضرورى للنمو الاقتصادى، ومن ثم التتمية الاقتصادية(هشام محمد عمارة،أحمد عبدالعليم

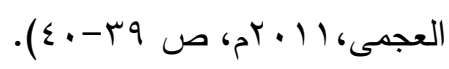
منع تكرار استخدام النفط سلاحا اقتصاديا أو سياسيا، وسلب الدول النفية، لا سيما العربية وعلى رأسها تلك الدول المتهمة بدعم الإرهاب امتبازا هاما ومؤثرا (سيد عاشور

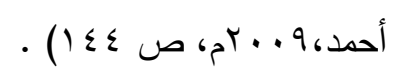

$$
\begin{aligned}
& \text { r.r. المجلد الناسع والأربعون، العدد الثاني عشر، جزء (V) ديسمبر } \\
& \text { الترقيم الدولي 0826-1110 }
\end{aligned}
$$




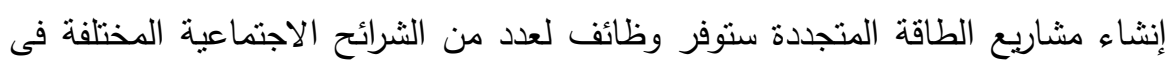
كثثر من المجالات والتخصصات، بداية من الأبحاث والتصنيع إلى الخدمات والتركيب

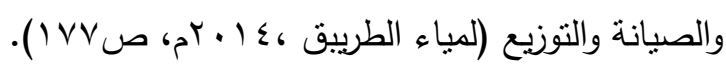

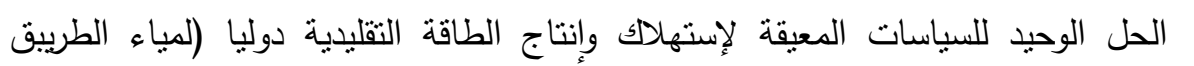

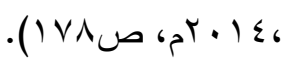

أصبحت الطاقات المتجددة لها تأثثر اقتصادى مهم فى التطبيقات الصناعية، منل توليد الكهرباء وتزويد المنازل والمبانى العامة بالطاقة وفى الاتصالات والملاحة والثبكات

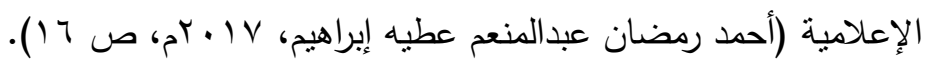

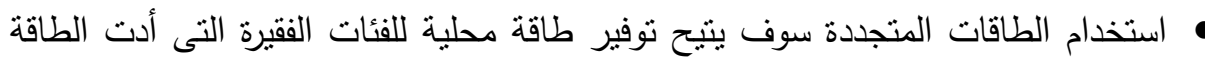

التقليدية إلى تقليل قدرتها بشكل حاد على تحسين ظروفها المعيشية (هشام محمد

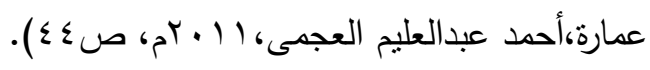

\section{إجبراءيت التراسة}

منهج البحث: نم استخدام المنهج الوصفي والاعتماد على الاسلوب التحليلى القائم على المنهج الاستقرائى لتكوين الإطار النظري للبحث وجمع البيانات باستخدام الهصادر المختلفة والتي تتمنل في الكتابات والدراسات الأكاديمية والإطلاع علي البيانات الرسمية الخاصة لئه بموضوع البحث، وكذللك الإطلاع علي المراجع والدوريات العربية والأجنبية وعلى مواقع الانترنت المختلفة.

\section{منهجية جمع المعلومات:}

أولاً: تحديد البيانات المطلوية للبحث: من أجل تحقيث أهداف البحث تم تحديد البيانات

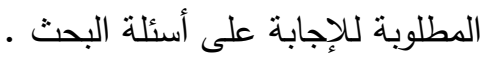

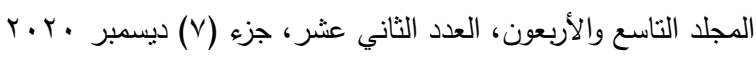

$$
\begin{aligned}
& \text { الترقيم الدولي 0826-1110 }
\end{aligned}
$$


ثناتياً: تحديد الجهات المنوط بها توفير هذه البيانات: لأنه لا توجد جهه واحدة منوط بها

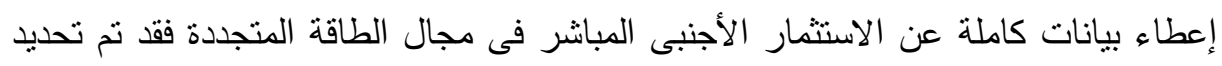

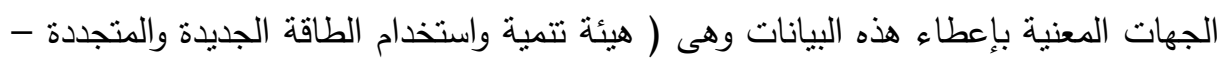
الهيئة العامة للاستتمار والمناطق الحرة - هيئة تتفيذ مشروعات المحطات المائية لتوليد الكهرباء بالإضافة إلى التقارير السنوية للجهات المعنية الأخرى والتى تتمنل فى تقارير جهاز شئون البيئة، نقارير الثركة القابضة لكهرباء مصر، تقارير الجهاز المركزى للتعبئة العامة والإحصاء) ثالثاً: مخاطبة هذه الجهات بثكل رسمي للحصول على البيانات: تم عمل خطابات معتمدة

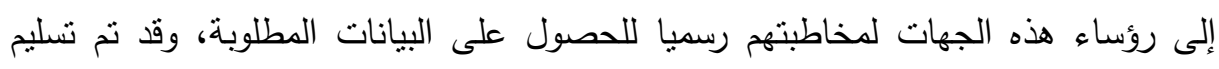

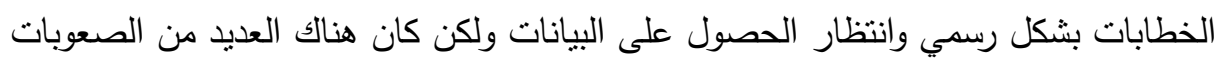

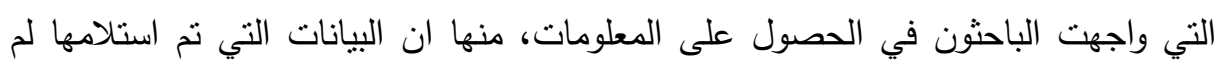

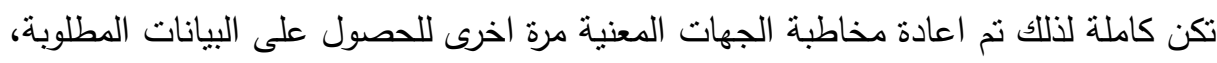

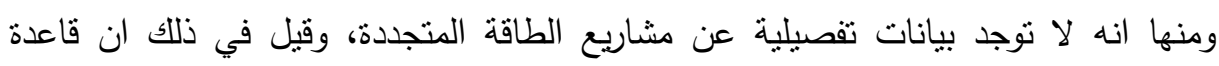

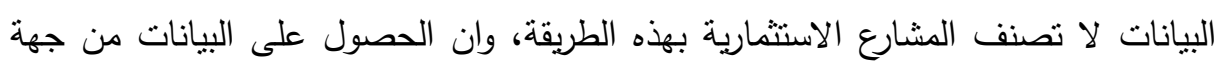
مثل هيئة تتمية واستخدام الطاقة الجديدة والمتجددة كان لابد من الذهاب إلى إدارة الحسابات

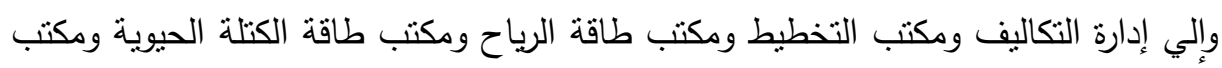
طاقة حراة باطن الأرض وإلى إدارة التدريب لكى نتمكن من الحصول على المعلومات لكل

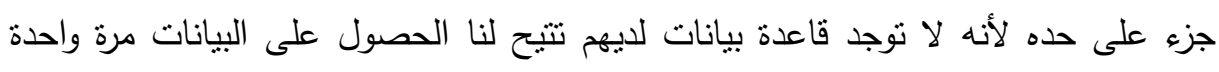

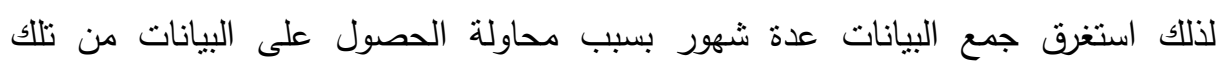
الجهات. رابعاً: معالجة البيانات وتفسيرها: تم الاعتماد على الاسلوب الاستقرائي في تحليل البيانات

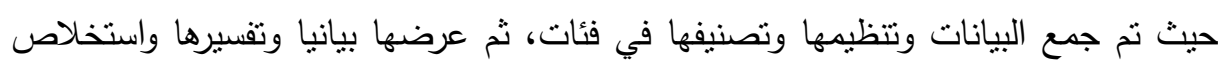
النتائج.

$$
\begin{aligned}
& \text { r.r. المجلد التاسع والأربعون، العدد الثاني عثر، جزء (V) ديسمبر } \\
& \text { التزقيم الدولي 0826- الترني الطداني }
\end{aligned}
$$




\section{مسورت المهمه}

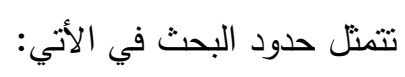

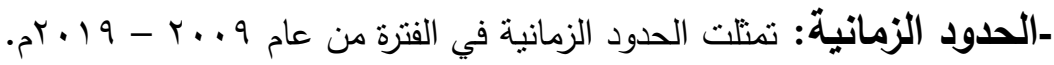

-الحدود المكانية: تمثلت الحدود المكانية في جمورية مصر العربية .

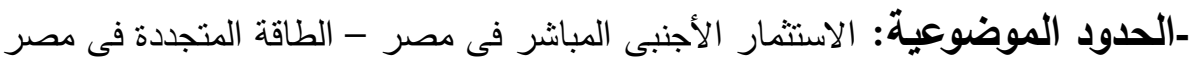

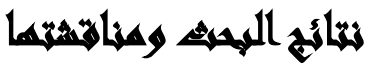

السؤال الأول : ما حجم تدفقات الاستثمار الأجنبى المباشر فى مصر خلال فترة الدراسة ؟

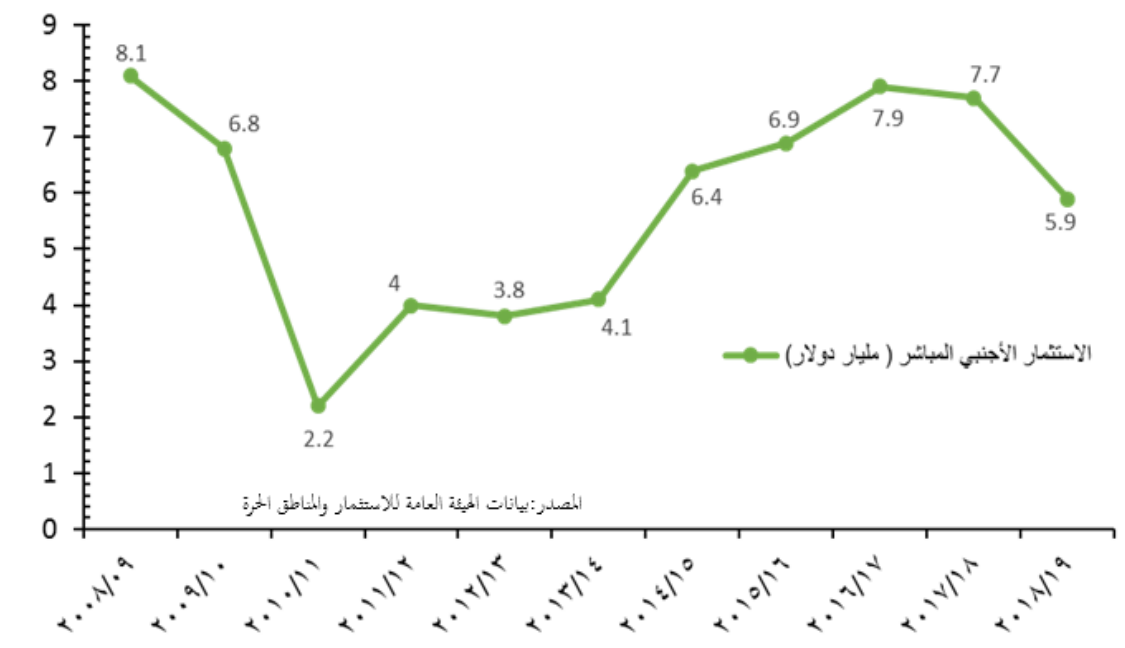

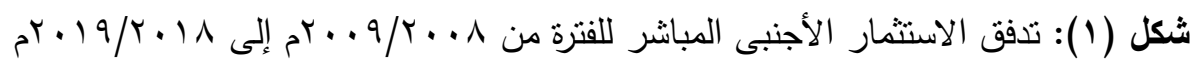
المصدر : بيانات الهيئة العامة للاستثمار والمناطق الحرة الكائرة

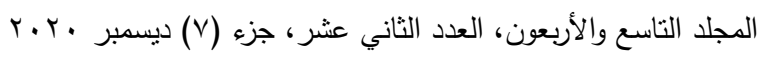

$$
\begin{aligned}
& \text { الترقيم الدولي 0826-0 الني }
\end{aligned}
$$


ينطلق الباحثون فى تفسير هذه البيانات من فرضية رئيسية مفادها أن الاستقرار السياسى

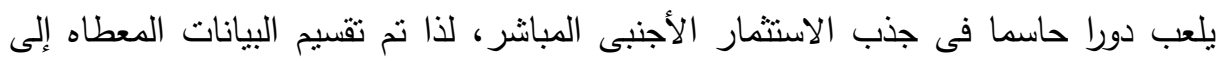

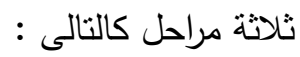
المرحلة الأولى: مرحلة الاستقرار السياسى النسبى: حيث نلاحظ من العرض السابق أن العام

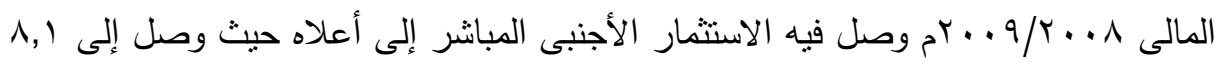

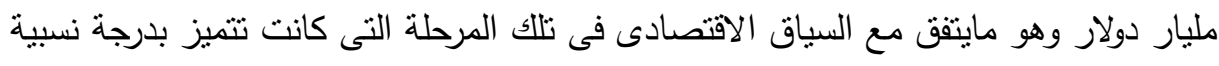

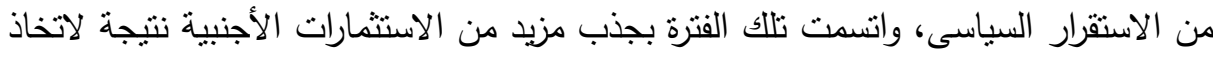

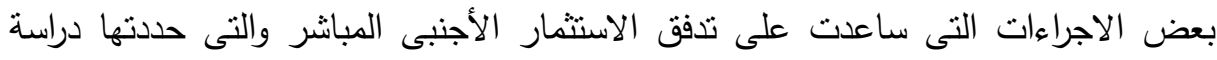

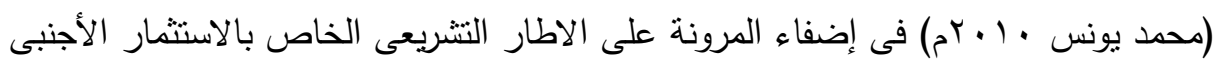
المباشر وتشهيل الاجراءات الإدارية المتعلقة به باختصار عددها وتكلفتها والوقت الهاء اللازم

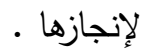

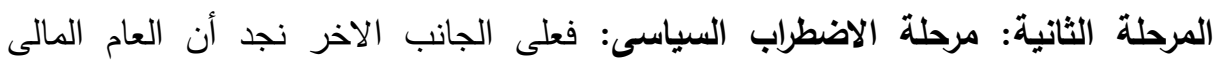

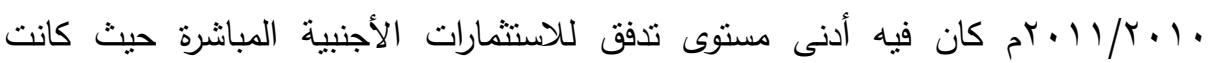
r,r rليار دولار فى نللك السنة، وهو ما جاء نتيجة لعدم الاستقرار السياسى خلال نلآك الفترة

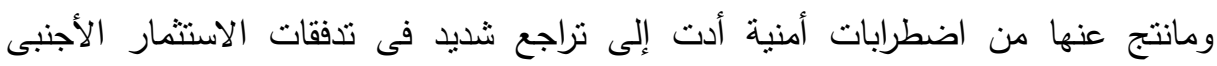

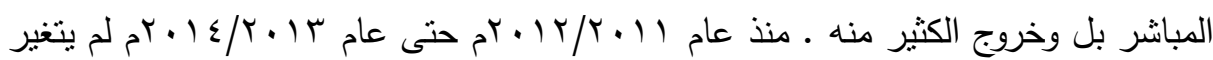

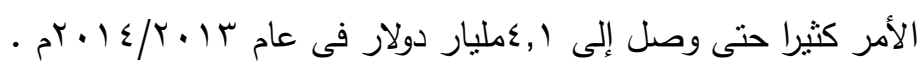

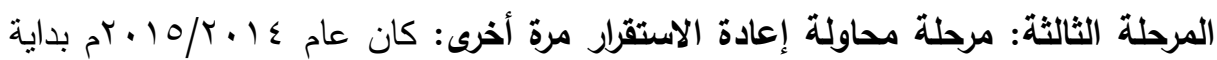

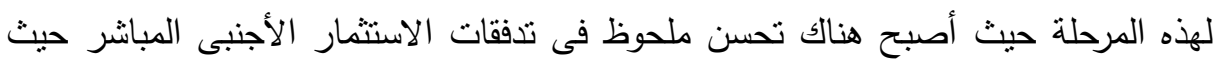

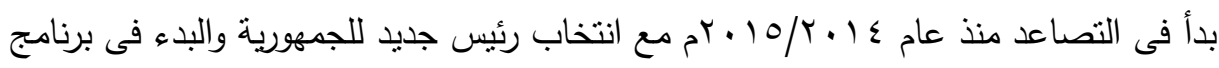
الاصلاح الاقتصادى الذى قامت به الحكومة المصرية منذ عام 0 • بام وإصدار عدة قوانين منل قانون الاستثمار الجديد وقانون تسهيل الحصول على التراخيص الصناعية فضلا عن الصن

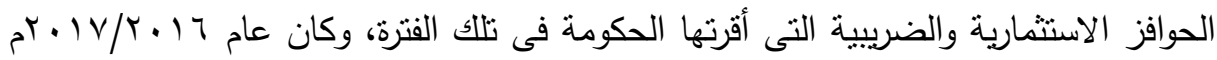

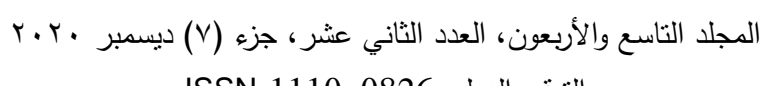


هو أعلى تدفق فى هذه المرحلة حيث وصل إلى V,9 مليار دولار ، وهو العام الذى نم فيه

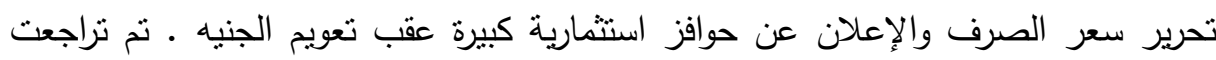
تدفقات الاستثمار الأجنبى المباشر بشكل تدريجى حتى وصلت إلى 9,0 همليار دولار فى العام

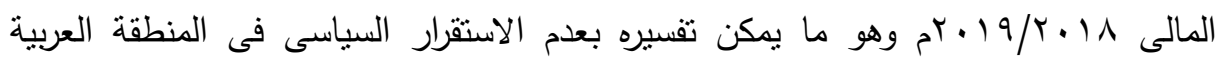

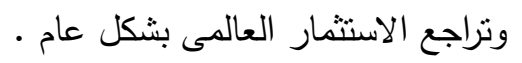

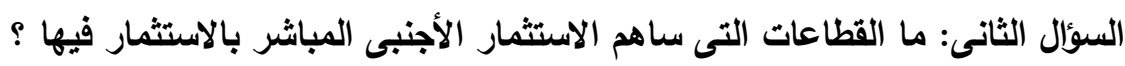

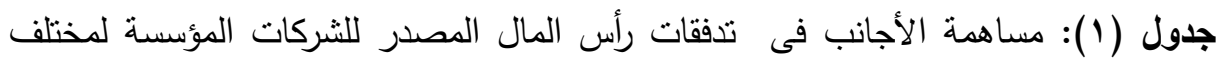

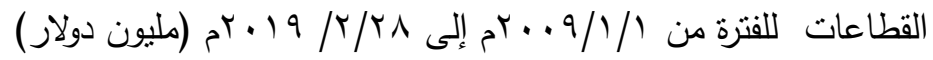

\begin{tabular}{|c|c|c|c|c|c|c|c|}
\hline القطاع / السنة & الاتكالات المطولوجيات & الانشائي & التمويلي & الذذمي & الزراعي & السياحي & الصناعي \\
\hline 2009 & 996.01 & 500.62 & 345.69 & 358.94 & 36.25 & 366.76 & 377.9 \\
\hline 2010 & 27.03 & 423.11 & 2092.79 & 149.35 & 1282.59 & $94.78-$ & 1263.23 \\
\hline 2011 & 16.38 & 256.59 & 168.71 & 479 & 204.2 & 71.08 & 264.67 \\
\hline 2012 & 14.19 & 30.29 & 394.33 & 438.29 & 37.97 & 30.22 & 825.8 \\
\hline 2013 & 199.53 & 48.43 & 916.4 & 353.08 & 153.22 & 12.2 & 366.9 \\
\hline 2014 & 6.51 & 496.81 & 366.86 & 574.81 & 61.88 & 165.18 & 733.14 \\
\hline 2015 & 35.12 & 949.96 & 661.22 & 415.06 & 84.18 & 137.78 & 1060.71 \\
\hline 2016 & 42.16 & 275.33 & 97.29 & 725.34 & 13.39 & 19.20- & 668.54 \\
\hline 2017 & 19.92 & 248.3 & 548.23 & 344.43 & 29.49 & 80.02 & 509.65 \\
\hline 2018 & 31.34 & 169.75 & 0.46 & 232.74 & 53.22 & $62.35-$ & 0.74 \\
\hline 2019 & 13.25 & 3.69 & 168.00 & 15.33 & 0.82 & 15.73 & 35.89 \\
\hline
\end{tabular}

المصدر: بيانات الهيئة العامة للاستثمار والمناطق الحرة. 
نستخلص من الجدول السابق أهم القطاعات التى جذبت الاستثمار الأجنبى المباشر

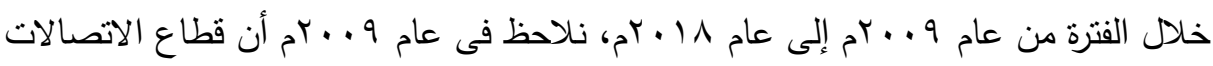

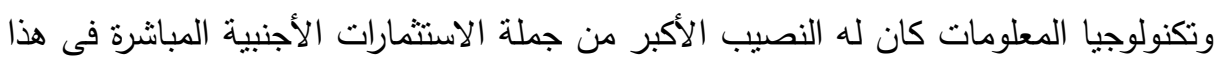

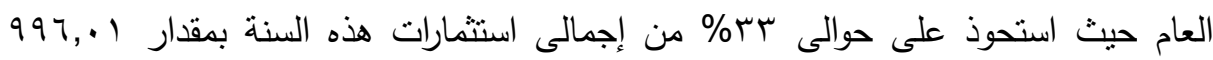
مليون دولار وعدد r ش شركة مؤسسة فى هذا العام، واشتمل قطاع الاتصالات وتكنولوجيا

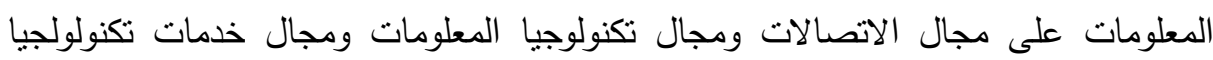
النظم واستحوذ مجال الاتصالات على حوالى ع 9\% من اجمالى استثمارات هذا القطاع بمقدار

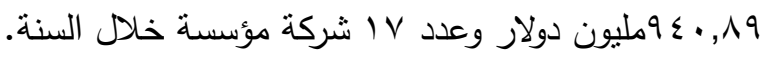

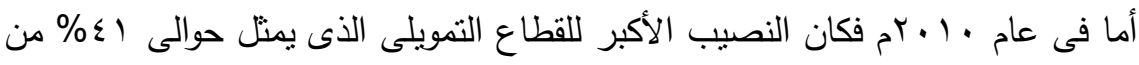

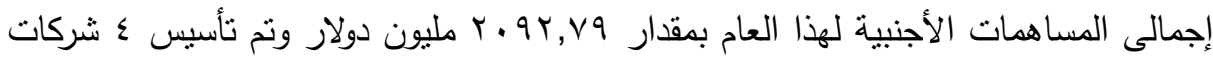
فى هذا العام، وتم اشتمال القطاع التمويلى على ثلاث مجالات وهما مجال البنوك، الخدمات

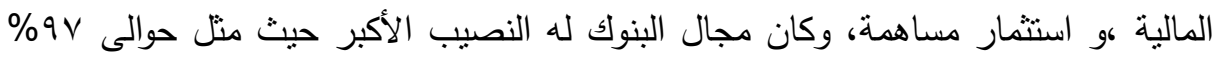

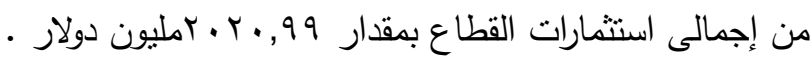
وحصل القطاع الخدمى على المركز الأول من حيث حجم الاستثمارات الأجنبية الوافدة

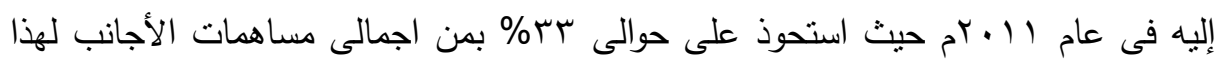

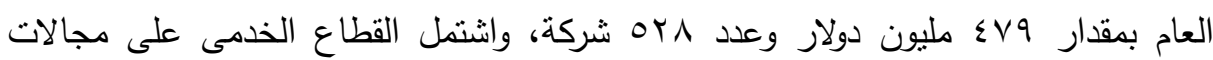

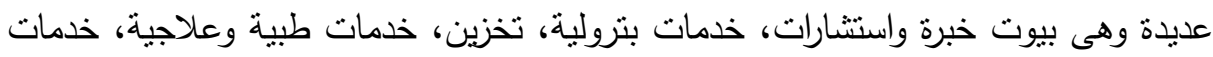

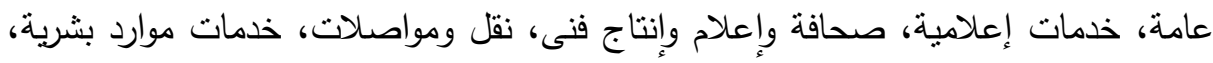

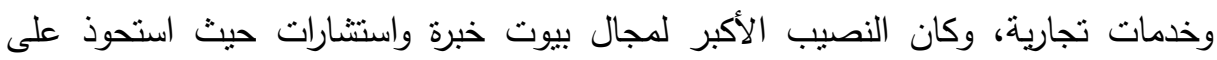

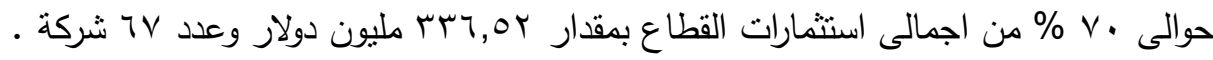

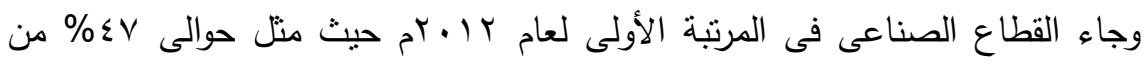

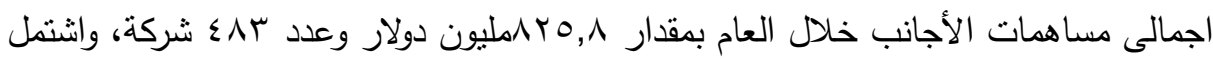
القطاع الصناعى على مجالات عديدة وهى المعدنية، الغذائية، الكيماوية ،مواد البناء، الدوائية،

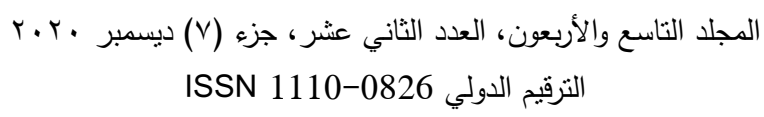


الغزل والنسيج، الهندسية، التعدين، والخشبية، واستحوذ مجال الصناعات الغذائية على حوالى

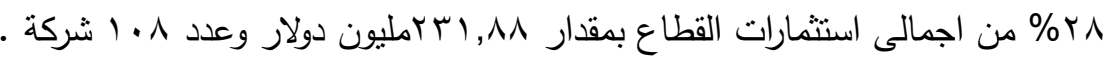

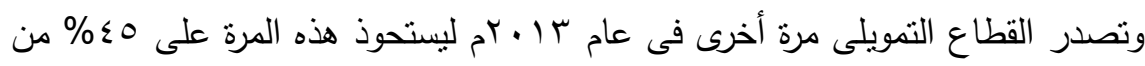

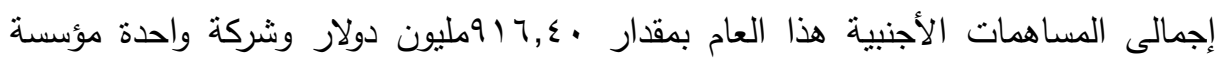
خلال السنة، واحتل مجال البنوك ثانية على نسبة حوالى 99\% من اجمالى المساهمات

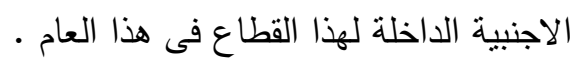

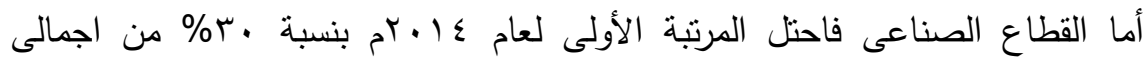

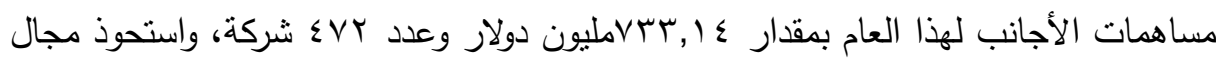

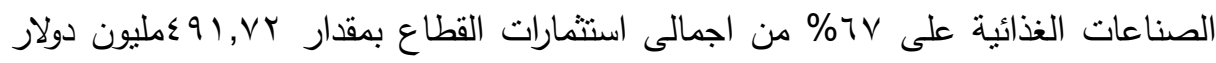
وعدد r ال الشركة .

وللمرة الثانية على التوالى والثالثة خلال فترة الدراسة احتل القطاع الصناعى المركز

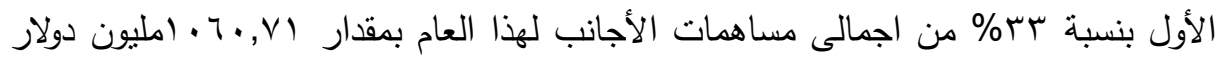

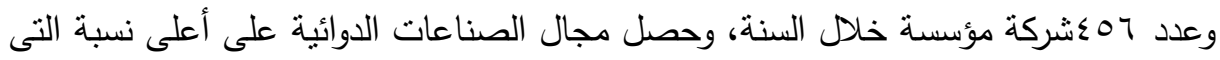

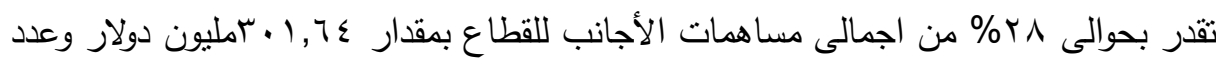

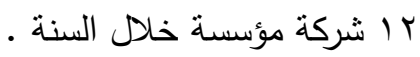

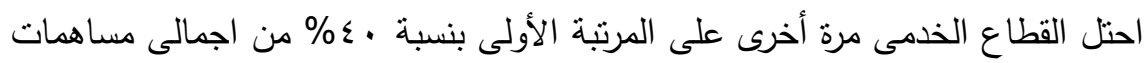

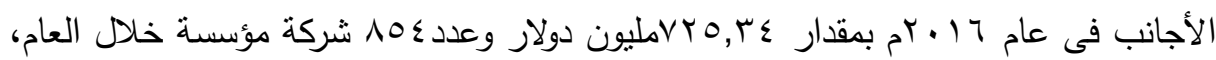

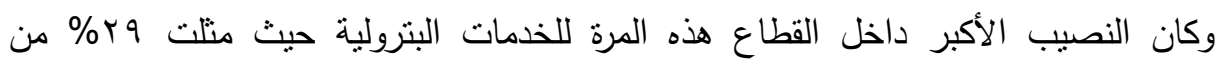

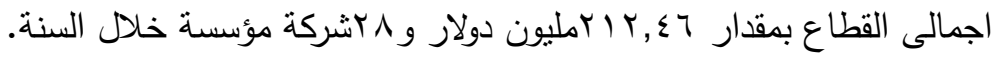

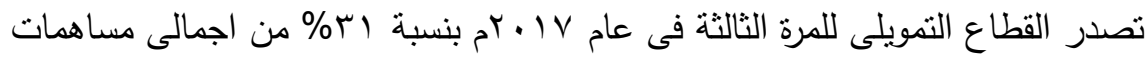

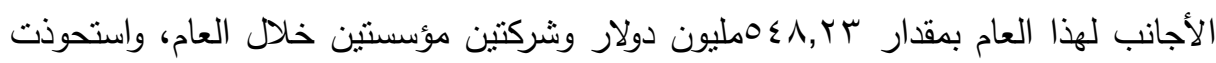

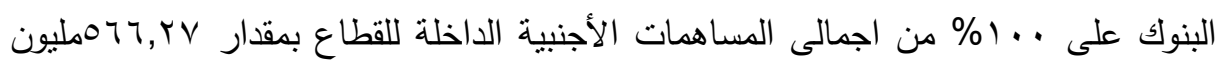

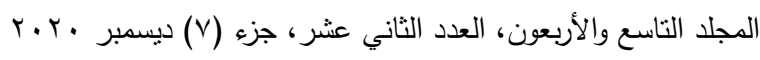

$$
\begin{aligned}
& \text { الترقيم الدولي 0826-1110 }
\end{aligned}
$$


أما فى عام ^1 ا • بم فقد استحوذ القطاع الخدمى للمرة الثالثة على المرتبة الأولى بنسبة

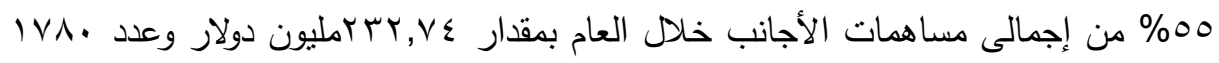

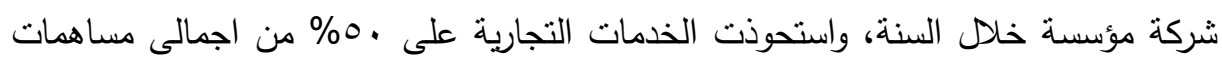

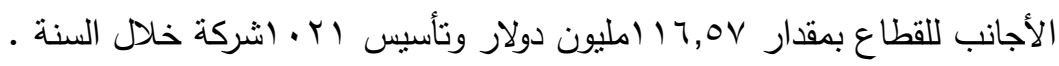

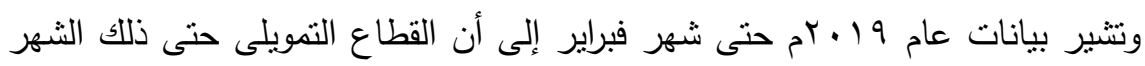
هو المتصدر بنسبة حوالى ب7\% من اجمالى مساهمات الأجانب لهذا العام حتى شهر فبراير

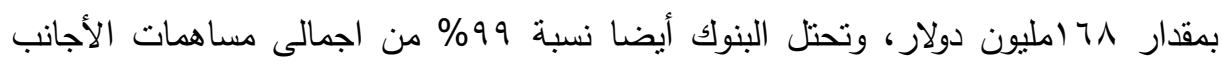

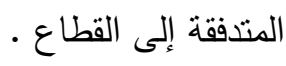

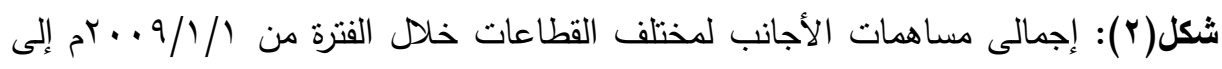

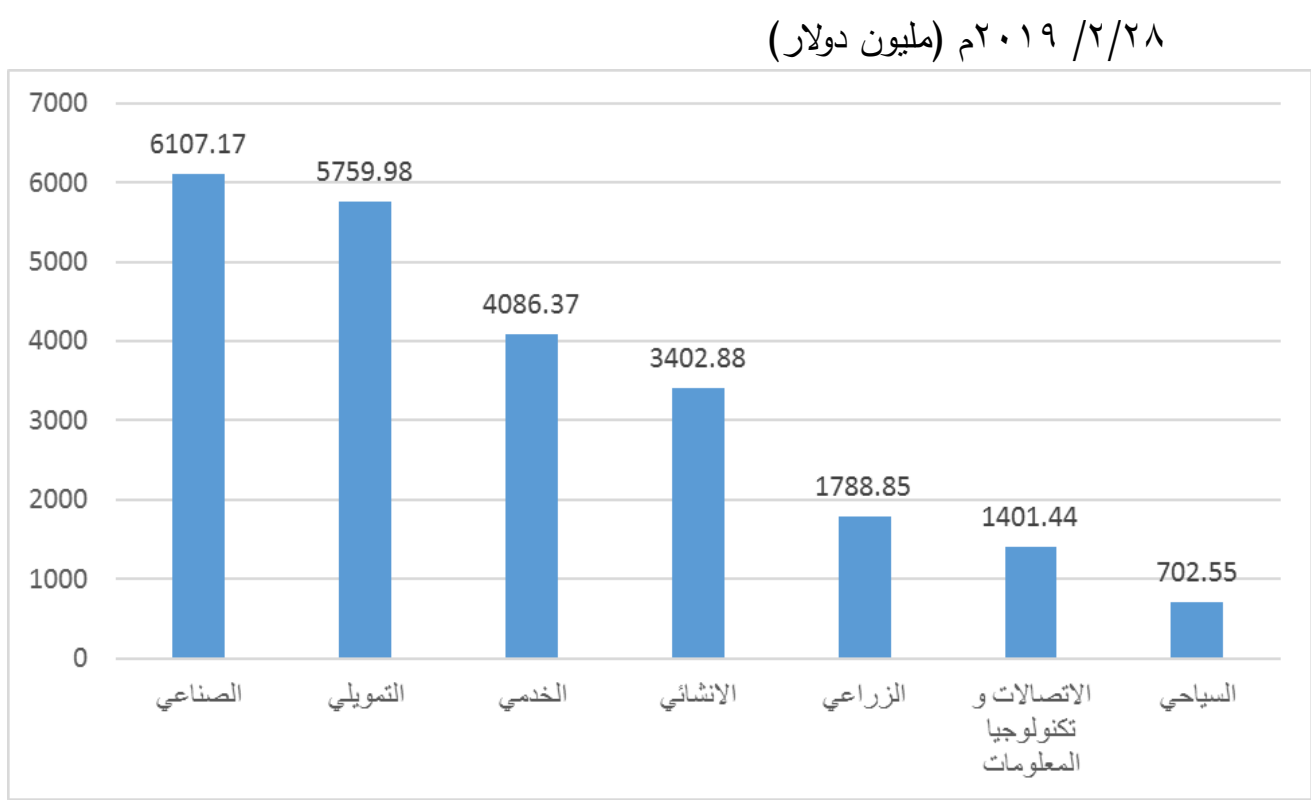

المصدر: بيانات الهيئة العامة للاستثمار والمناطق الحرة.

$$
\begin{aligned}
& \text { r.r. المجلد التاسع والأربعون، العدد الثاني عثر، جزء (V) ديسمبر }
\end{aligned}
$$

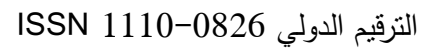




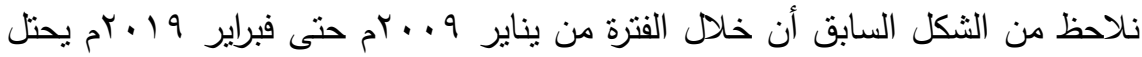
القطاع الصناعى المرتبة الأولى بنسبة بr\% من إجمالى المساهمات الأجنبية خلال الفترة،

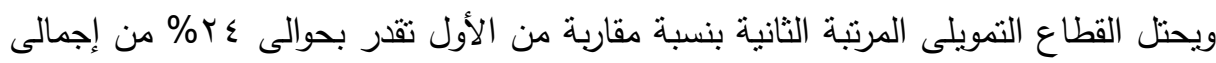

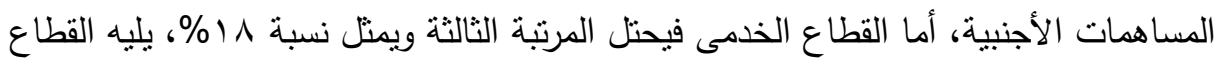

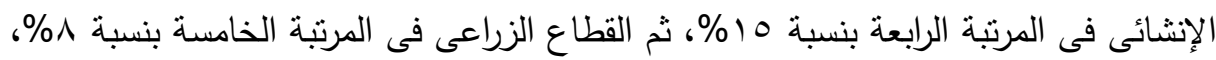

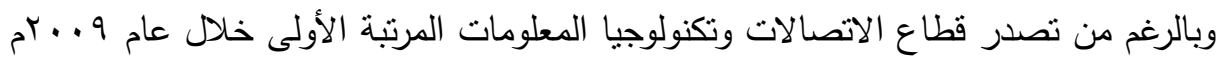

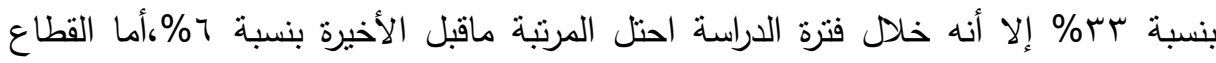
الذى احتل المرتبة الأخير هو القطاع السياحى بنسبة بـ\% من إجمالى مساهمات الأجانب

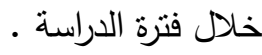

السؤال الثالث: ما هو حجم الاستثمار الأجنبى المباشر فى مجال الطاقة فى مصر؟

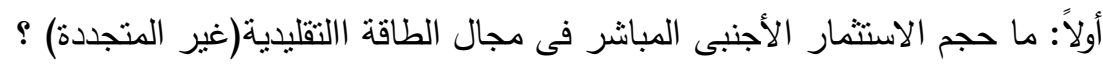

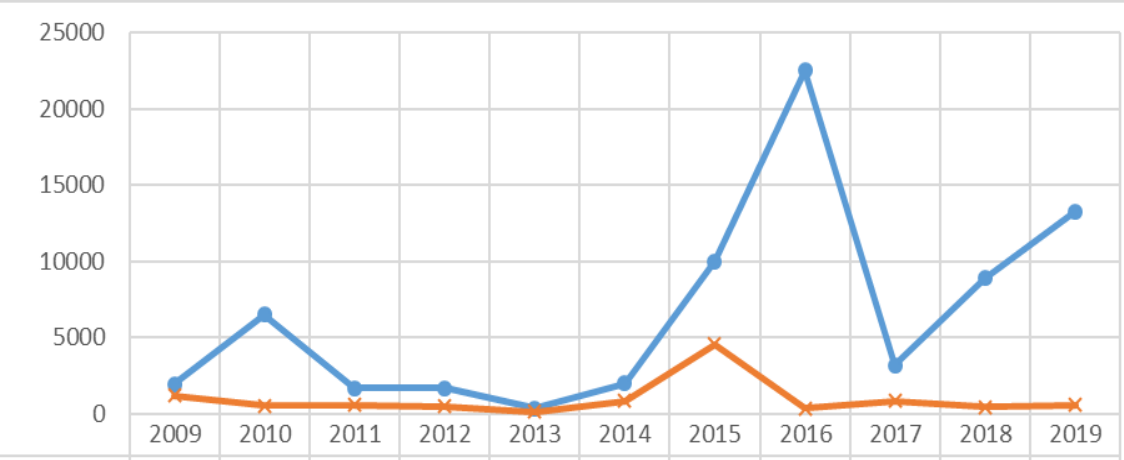

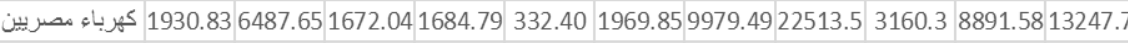

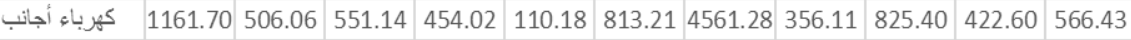

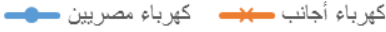

شكل (r): مساهمة المصريين والأجانب فى محطات الكهرباء من الطاقة التقليدية للفترة من

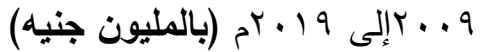

المصدر : بيانات الهيئة العامة للاستثمار والمناطق الحرة 


\section{مجلة العلوم البيئية \\ معهد الدراسات والبحوث البيئية - جامعة عين شمس للئس \\ فاطمة الزهراء صلاح الدين محمود السعيد وآخرون}

نلاحظ من الثكل السابق تقارب استثمارات المصريين والأجانب حتى عام 10 • بم، ثم

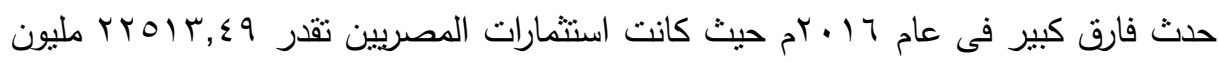

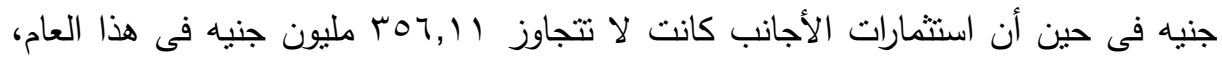

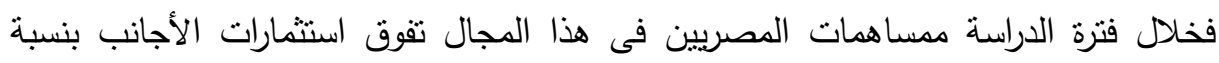
تقدر بحوالى هNV من اجمالى الاستثمارات، وهو ما يمكن تفسيره بأن الاحتباج الثديد للطاقة

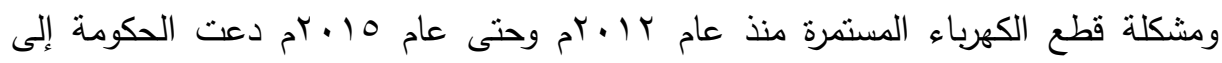

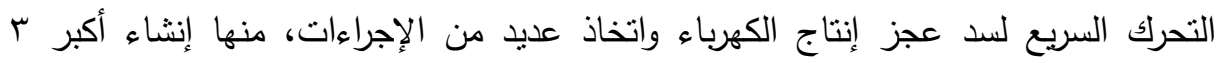
محطات لتوليد الكهرباء بالعالم بالتعاون مع شركه سيمنز الألمانية وهى(الهيئة العامة

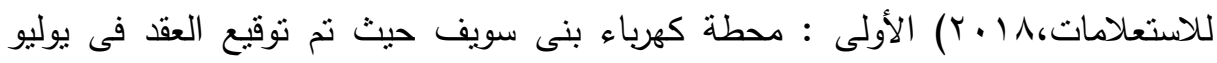

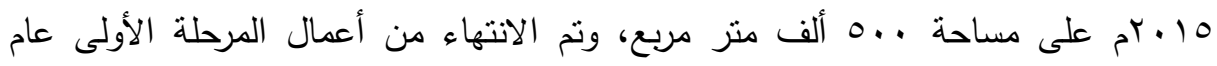

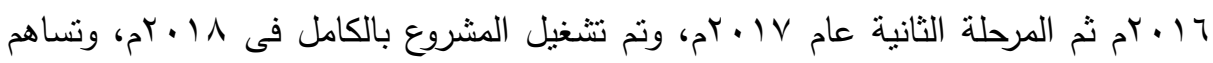

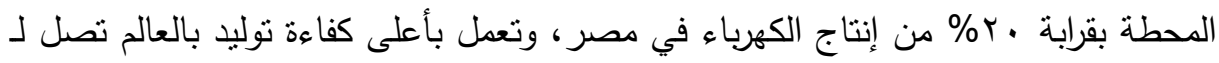

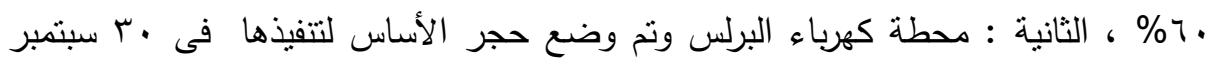

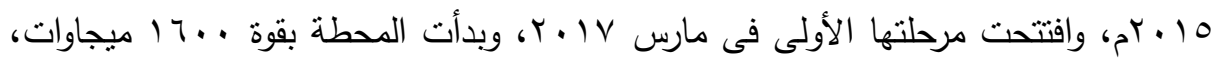

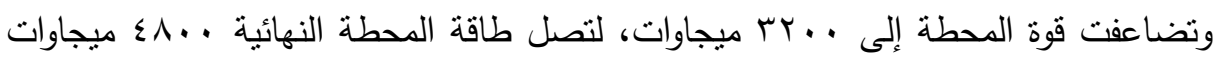

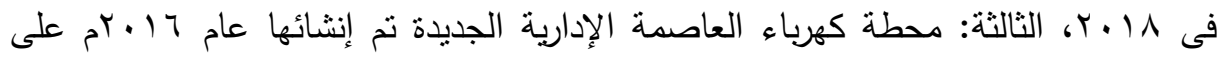

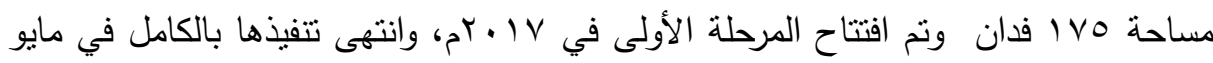

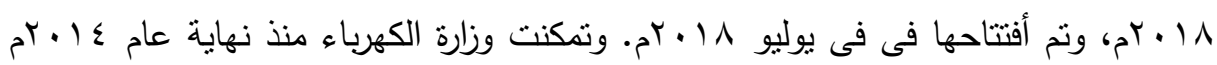

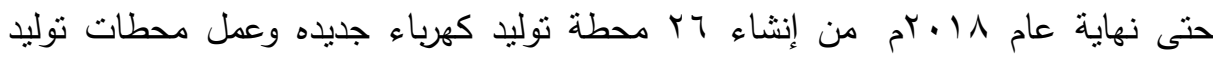
متتقلة لأول مرة في مصر في أماكن مختلفة كل ذلك فى سبيل الحفاظ على احتى احتباجات المواطنين من الطاقة، فتحولت حالة مصر من عجز فى الكهرباء إلى فائض إنتاج يقدر

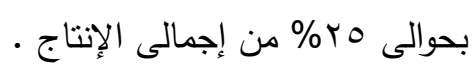

$$
\begin{aligned}
& \text { r.r. المجلد الناسع والأربعون، العدد الثاني عشر، جزء (V) ديسمبر }
\end{aligned}
$$

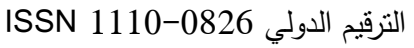


ثانيا: ما حجم الاستثمار الأجنبى المباشر فى مجال الطاقة المتجدة فى مصر ؟

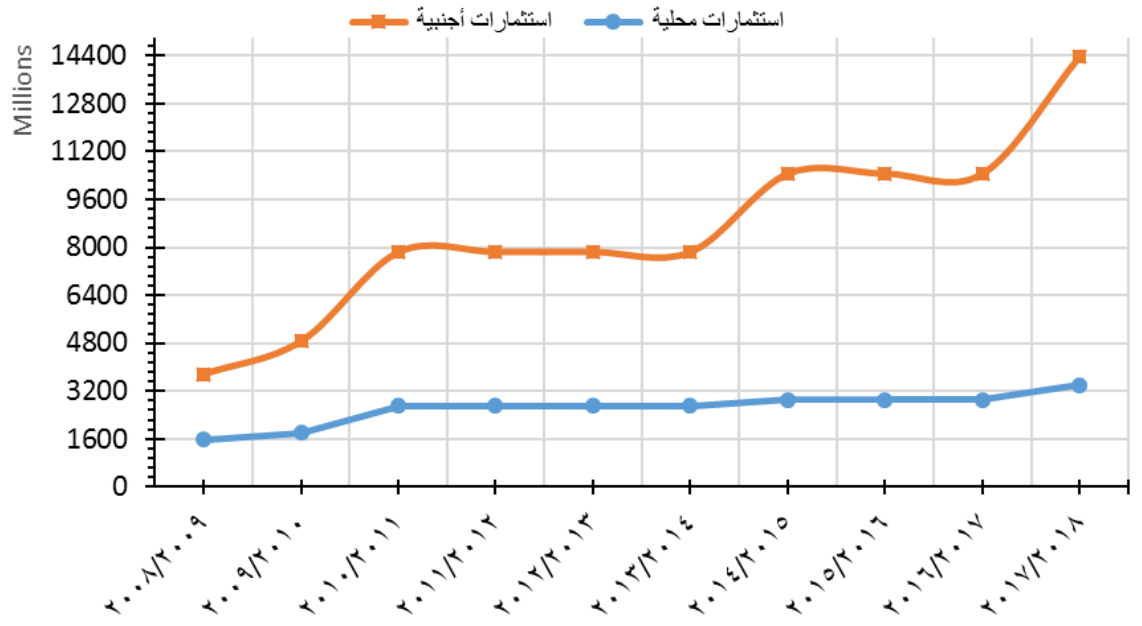

شكل(•): حجم الاستثمارات المحلية والأجنبية للطاقة المتجددة للمشروعات الحكومية المصدر : بيانات هيئة تتمية واستخدام الطاقة الجديدة والمتجددة

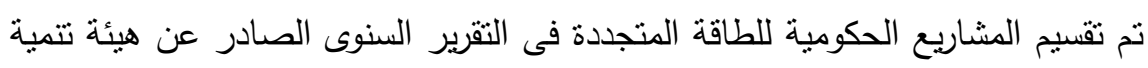

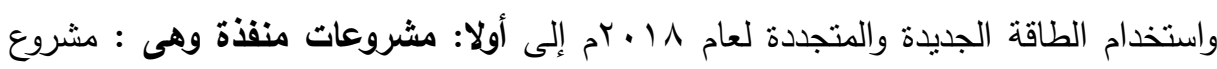

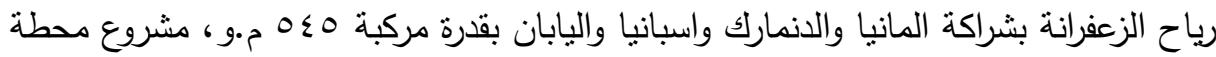
رياح جبل الزيت ا بشراكة المانيا وبنك الاستثمار الأوروبى والمفوضية الأوروبية بقدرة مركبة ونية

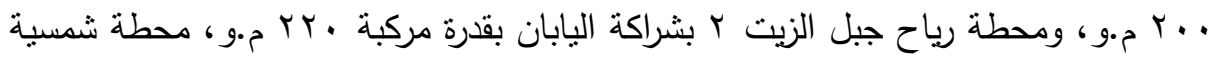

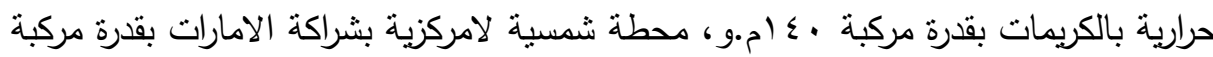
r r م.و ـ ثانيا: مشروعات تحت التففيذ وهى : محطة رياح جبل الزيتس بشراكة اسبانيا بقدرة

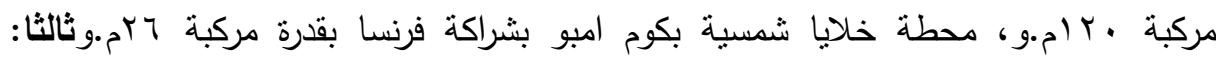
مشروعات تحت الاراسة وهى : محطة رياح خليج السويس ا بشراكة المانيا وبنك الاستثمار

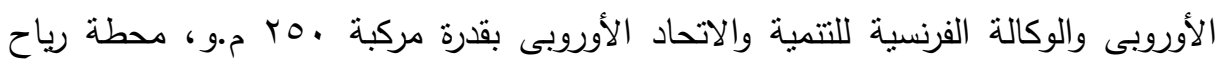
558

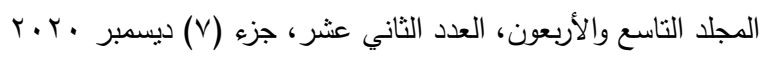

$$
\begin{aligned}
& \text { الترقيم الدولي 0826-1110 }
\end{aligned}
$$


خليج السويس ץ بشراكة فرنسا بقدرة مركبة . . F م.و ، محطة خلايا شمسية بالغردقة بشراكة

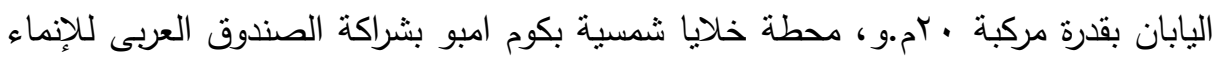

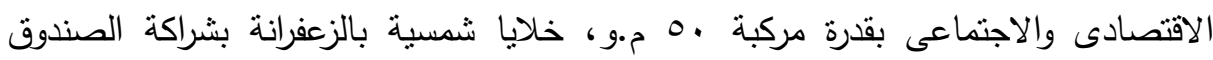

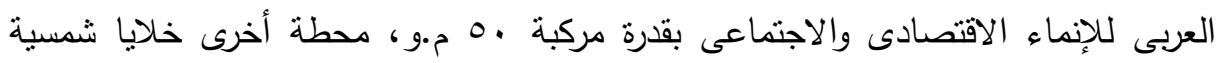

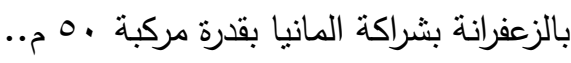
ونلاحظ من الثكل السابق المساهمات الأجنبية فى المشاريع الحكومية للطاقة المتجددة والتى تتفوق بكتير على مساهمات المصريين حيث أنه فى خلال فترة الدراسة تقدر نسبة

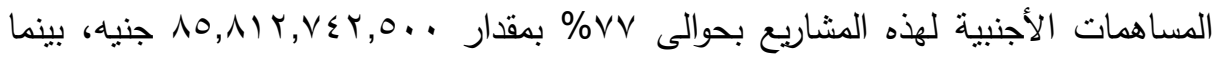
تقدر نسبة المساهمات المصرية بحوالى بr\% فقط من إجمالى استثمارات المشاريع الحكومية

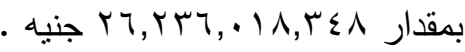

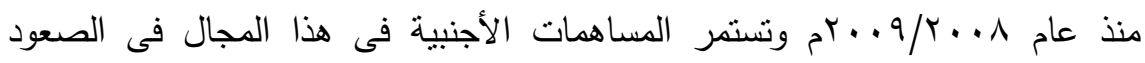

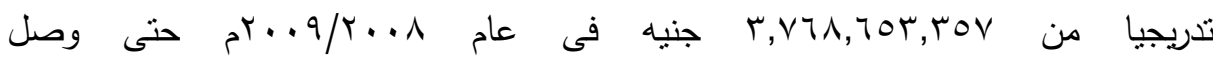

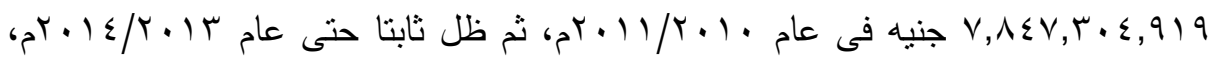

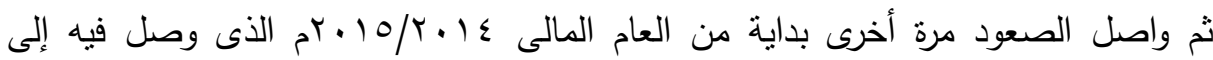

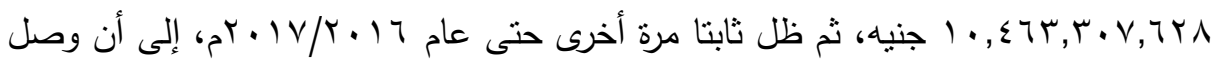

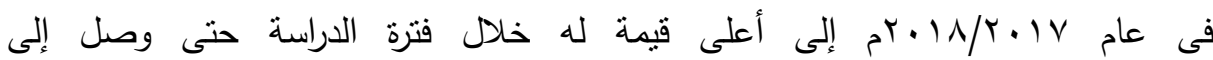
(

على الجانب الاخر نجد أن المساهمات المحلية هنا تصاعدت تصاعدا ضئيلا منذ عام

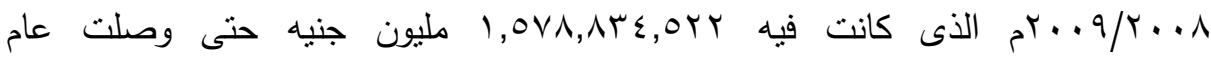

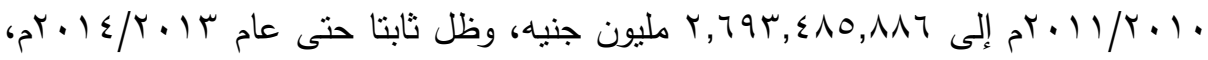

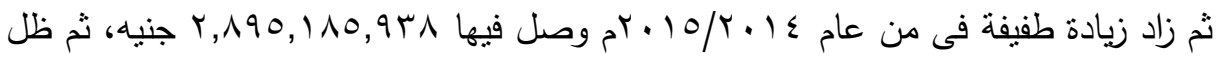

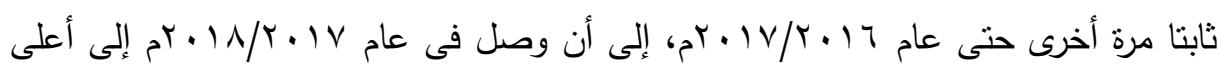

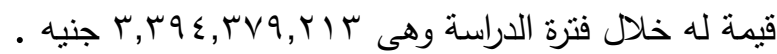

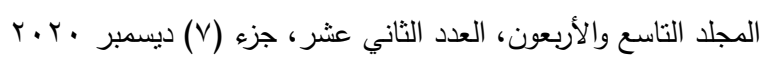


مجلة العلوم البيئية

معهد الدراسات والبحوث البيئية - جامعة عين شمس لهم

فاطمة الزهراء صلاح الدين محمود السعبد وآخرون

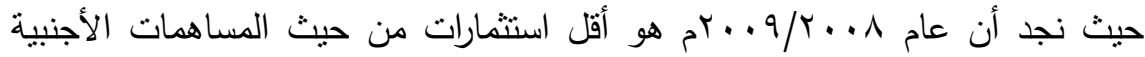

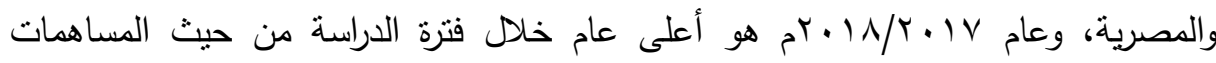

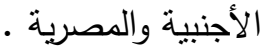

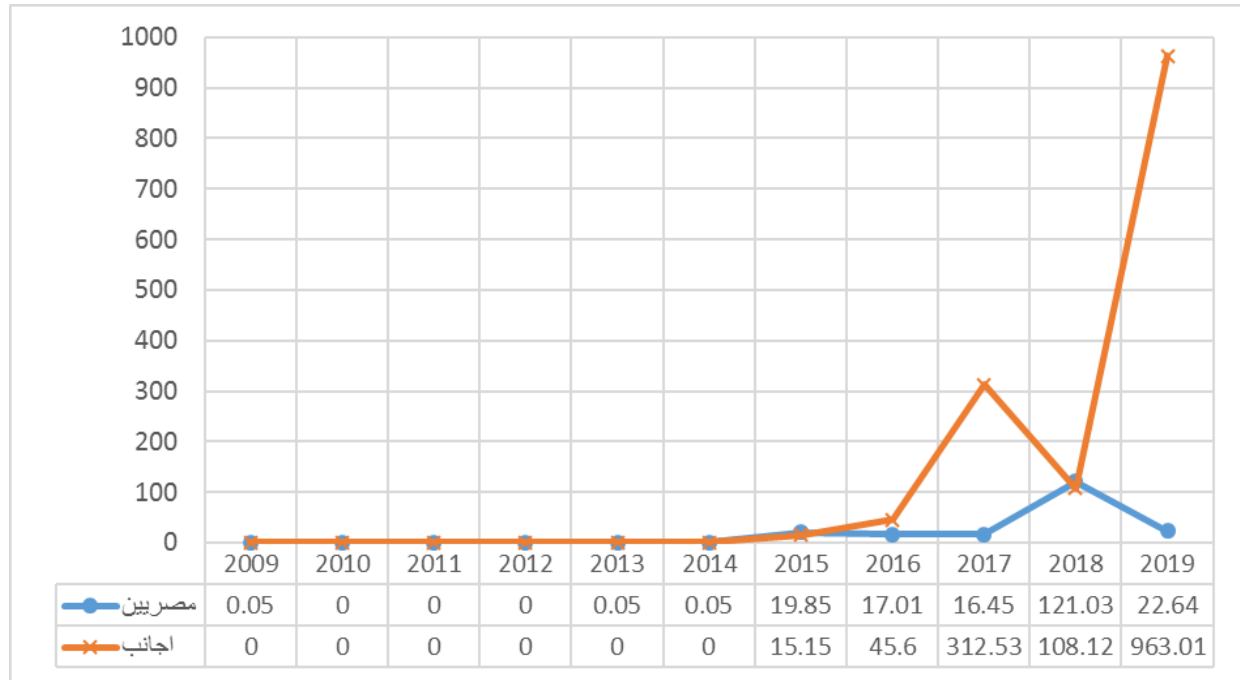

شكل(†): حجم الاستثمارات المحلية والأجنبية للطاقة المتجدة لمشاريع القطاع الخاص (بالمليون جنية)

المصدر : بيانات الهيئة العامة للاستثمار والمناطق الحرة .

تم تقسيم مشاريع القطاع الخاص فى مجال الطاقة المتجددة فى التقرير السنوى الصادر عن هيئة تتمية واستخدام الطاقة الجديدة والمتجددة لعام ^1 • بام إلى : أولا: مشروعات منفذة وهى : محطة خلايا شمسية بنظام صافى القياس بقدرة مركبة ـ بام.و ،

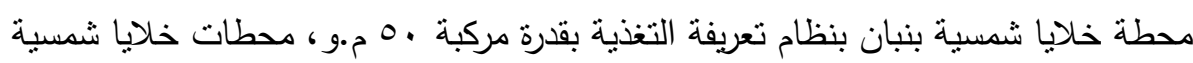

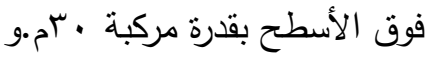

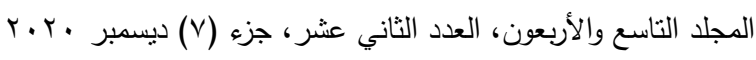

$$
\begin{aligned}
& \text { الترقيم الدولي 0826-0 الني }
\end{aligned}
$$


رابعا : مشروعات مخططة : محطة رياح خليج السويس بنظام البناء والتملك والتشغيل بقدرة

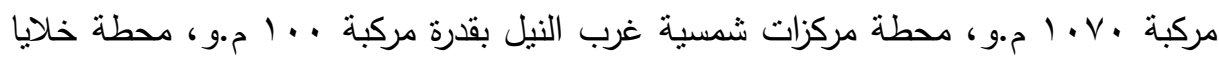

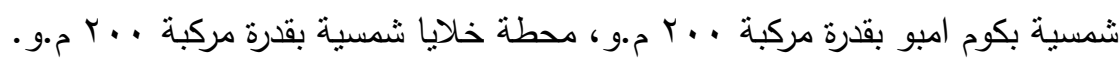

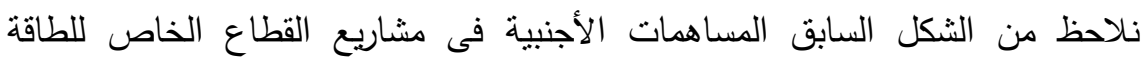
المتجددة والتى تفوق مساهمات المصريين خلال فترة الدراسة حيث تقدر نسبة المنافئ المساهمات

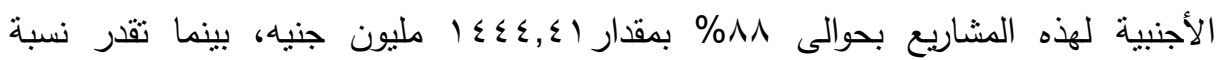

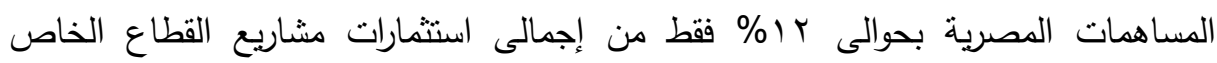

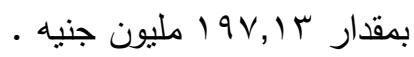

استمرت مساهمات الأجانب منعدمة فى مشاريع القطاع الخاص الخاصة بالطاقة

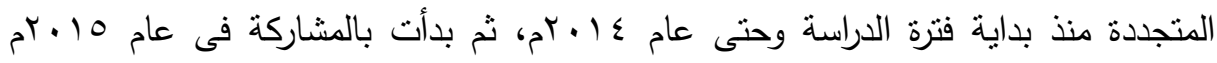

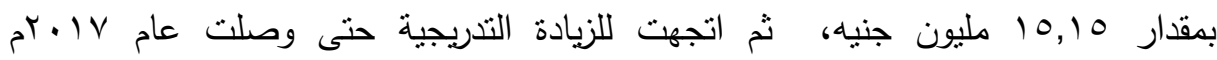

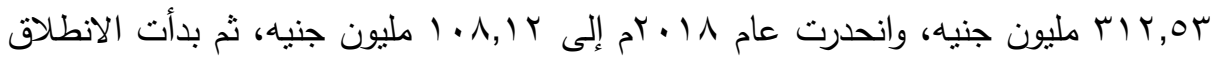

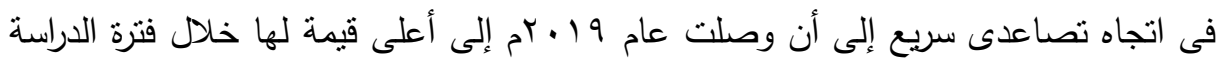

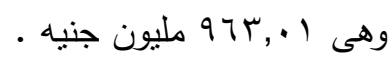

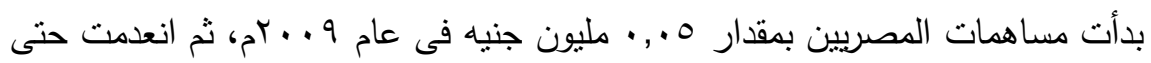

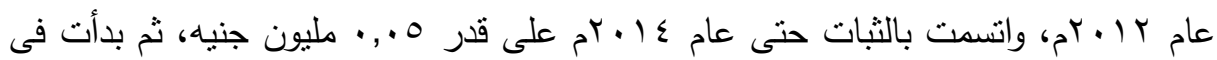

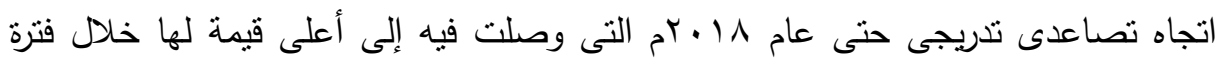

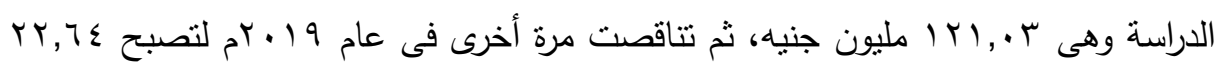
مليون جنيه .

نلاحظ من الثكلين (0)؛(7) أن تطورت استثمارات الطاقة المتجددة خلال فترة الدراسة زادت بشكل ملحوظ سواء بالمساهمات الأجنبية أو المصرية، فهل انعكس ذللك على تطور فى انى 


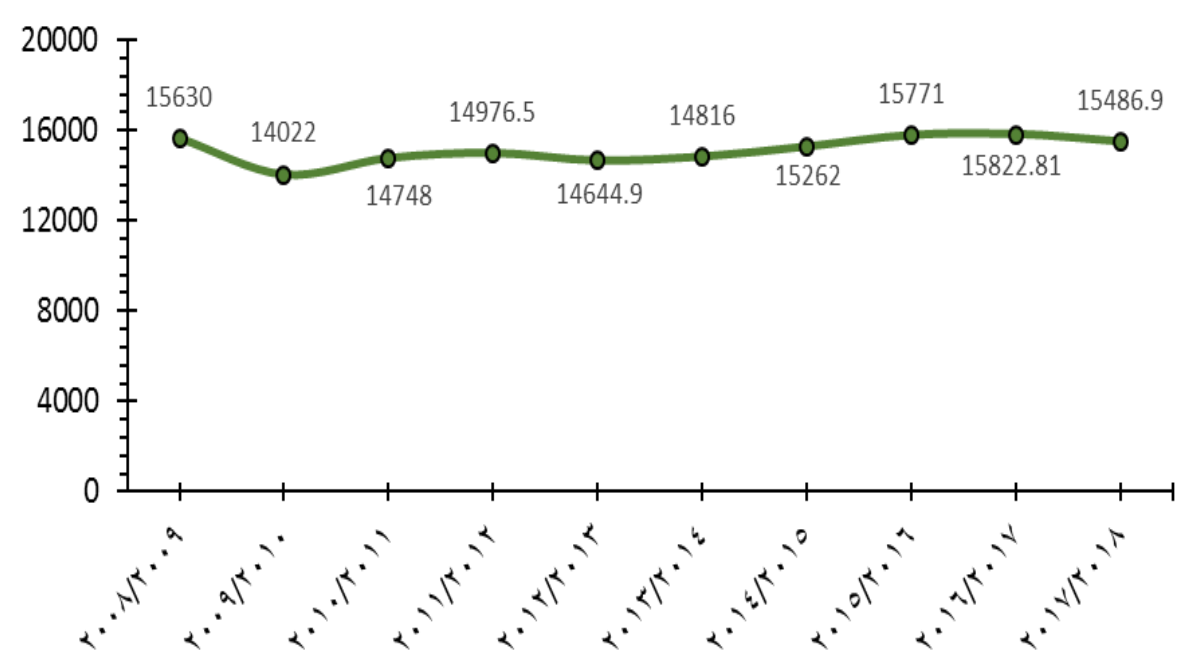

شكل(V): إجمالى حجم انتاج الطاقة المنتجة من الثمس والرياح والمياه خلال الفترة من

$$
\text { م }
$$

المصدر: بيانات تقارير الثركة القابضة لكهباء مصر سنوات مختلفة

لم ينعكس تطورات حجم استثمارات الطاقة المتجددة خلال فترة الدراسة على الإنتاج

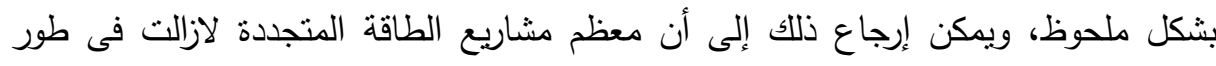

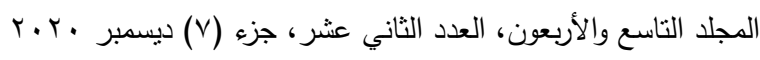

$$
\begin{aligned}
& \text { الترقيم الدولي }
\end{aligned}
$$




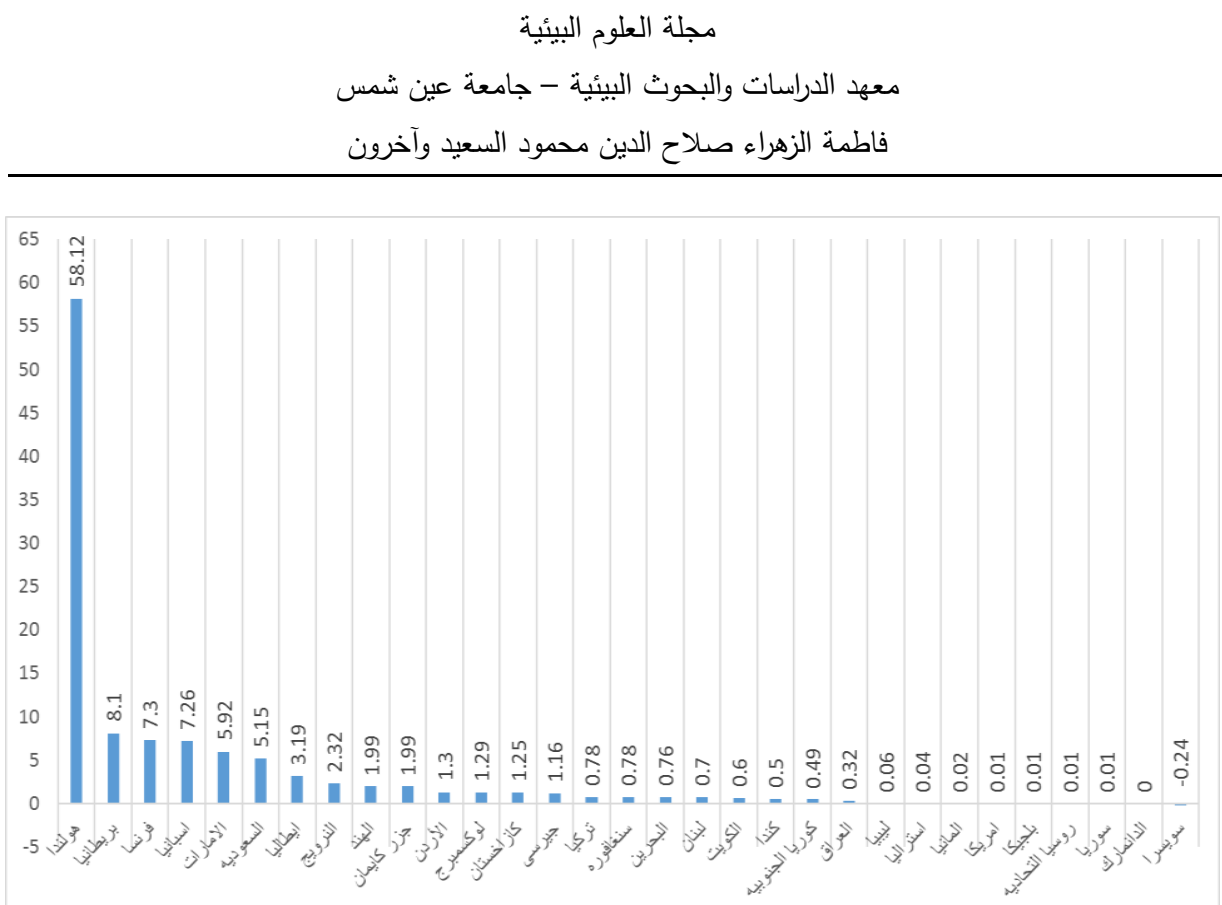

شكل(^): مساهمة الدول الأجنبية المستثمرة فى مصر فى مجال الطاقة المتجددة ( بالمليون

المصدر: بيانات الهيئة العامة للاستثمار والمناطق الحرة.

نلاحظ من شكل(^) أن هولندا هى الأقوى مشاركة فى استثمارات الطاقة المتجددة فى لهى مصر، حيث تستحوذ وحدها على نسبة حوالى به\% من إجمالى الاستثمارات الأجنبية المباشرة فى مجال الطاقة المتجدة فى مصر تليها بريطانيا ثم فرنسا ثم اسبانيا بنسب مقاربة من بعضهما، ثم الإمارات فالسعودية وتستمر النسب فى التضاؤل حتى نصل إلى سويسرا التى

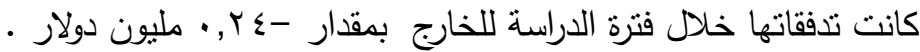




\section{zall}

أحمد حلمي مصطفي مجاهد (•(Y)، تقييم دور الاستثمار الأجنبي المباشر في تحقيق الأهداف التتموية في مصر، رسالة ماجستير، قسم الاقتصاد، كلية التجارة،

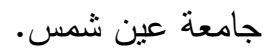

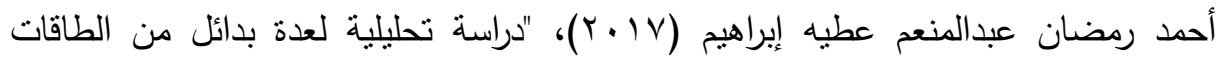

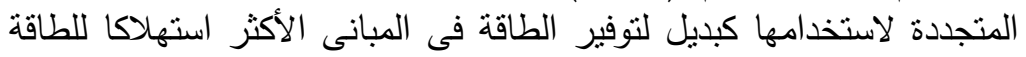

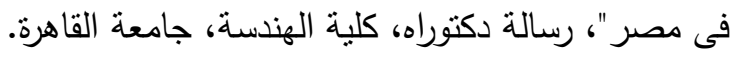

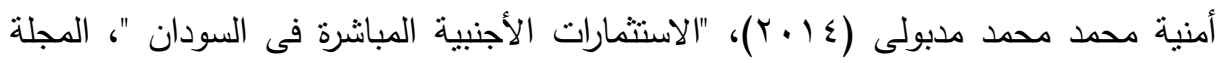
العلمية للاقتصاد والتجارة ، العدد الأول، كلية التجارة، جامعة عين شمس ل

أنور عبد الخالق، محمد عباس (9V^) ()، "المناطق الحرة" ( القاهرة : المنظمة العربية للعلوم

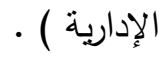

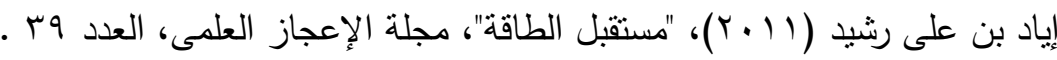

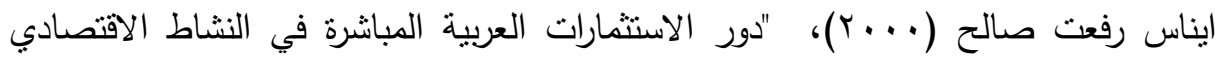

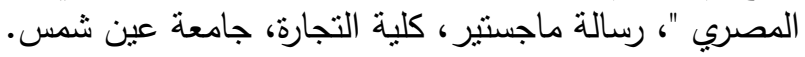

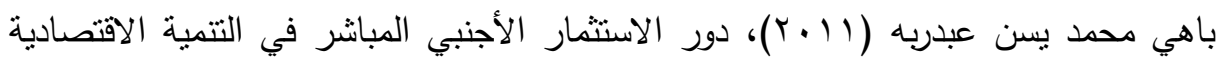

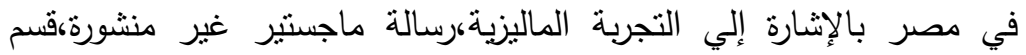

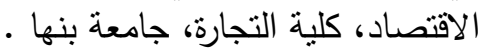

بنك مصر (99v1)، "قضايا الاستثمار الأجنبى المباشر فى البلدان النامية:نظرة تحليلية

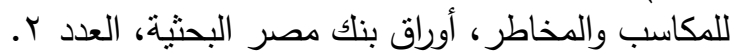

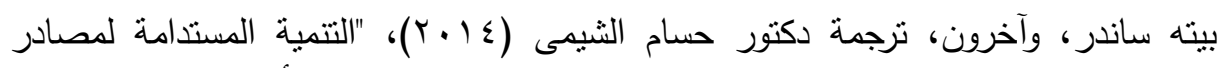
الطاقة المتجددة .. الثمس-الرياح-المياه-حرارة باطن الأرض"، الثرن، مجموعة النيل

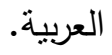

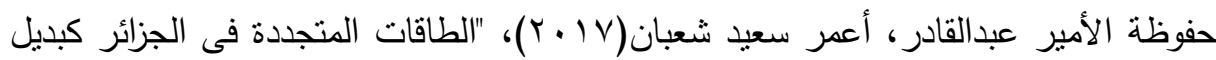

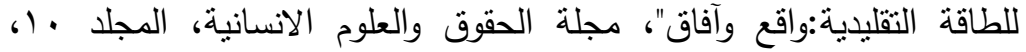
ملحق

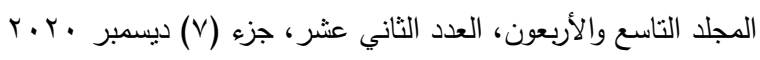

$$
\begin{aligned}
& \text { الترقيم الدولي 0826-1110 }
\end{aligned}
$$




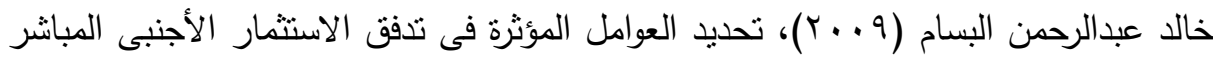

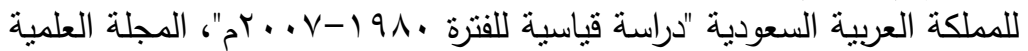
للاقتصاد والتجارة، كلية التجارة، جامعة عين شمس، العدد الثانى. للعن.

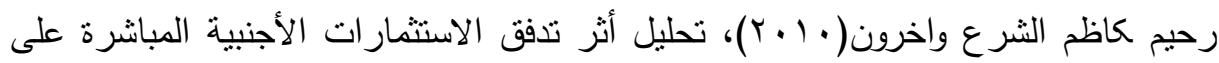

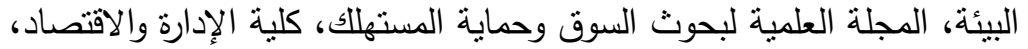

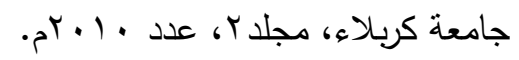

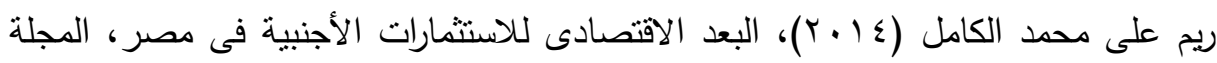

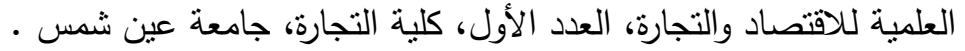

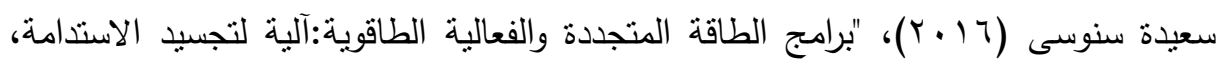

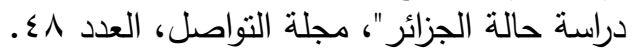

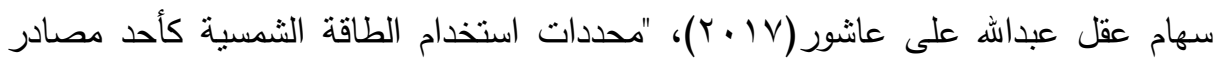

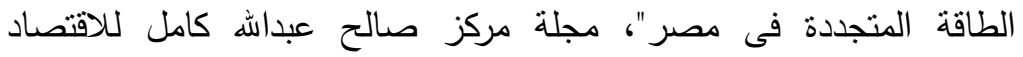

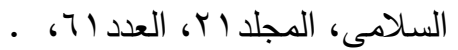

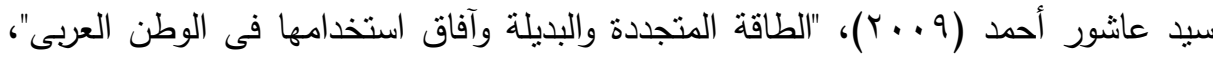

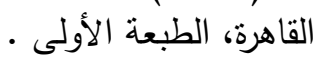

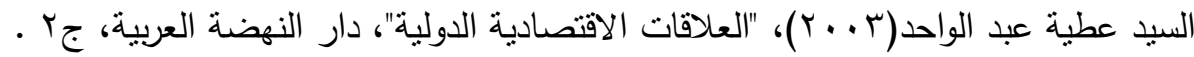

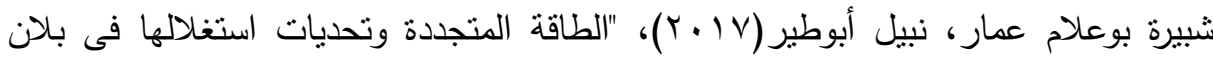

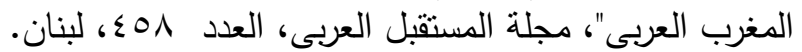

عبدالفتاح محمد عبدالفتاح (10 ( 10) ،"مناخ الاستثمار في مصر"، المؤتمر الضريبي الثاني

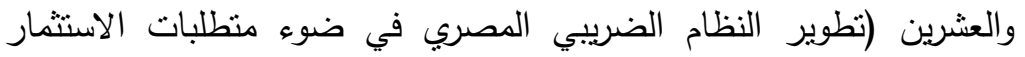

$$
\text { • والتتمية ) }
$$

عمر البيلى، خديجة الأعسر(ع991) ،"دور الاستثمار الأجنبى الخاص المباشر فى دعم

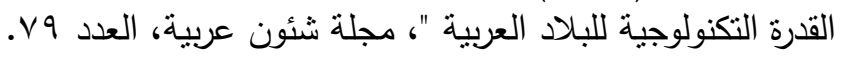

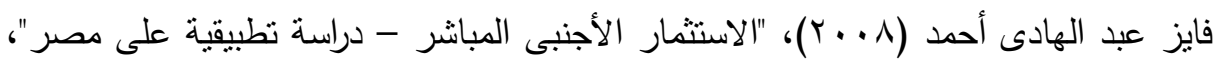

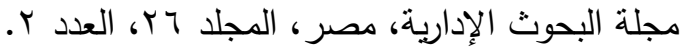

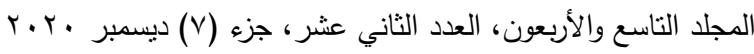

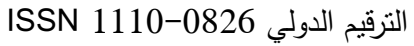




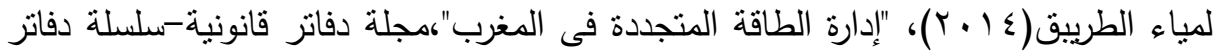

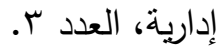

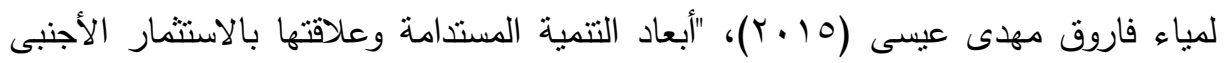

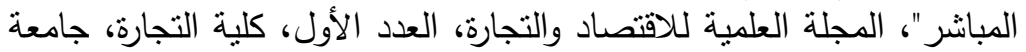

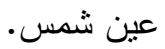

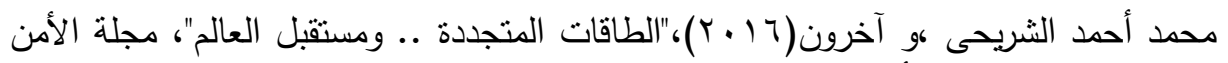

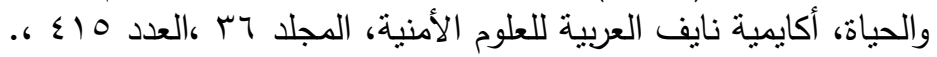

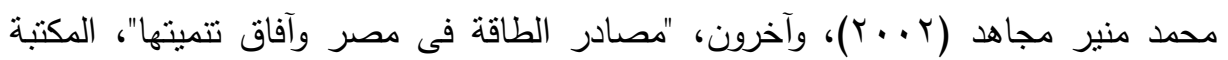

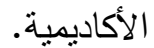

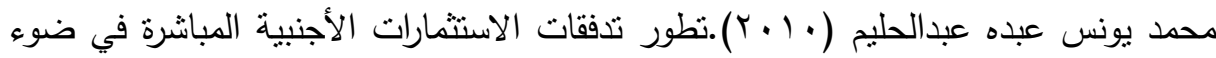

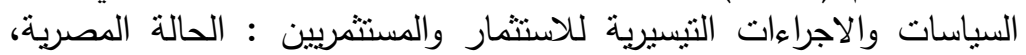

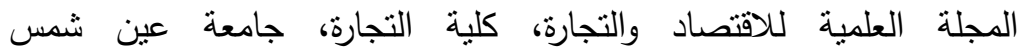
•

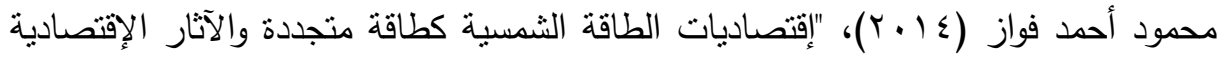

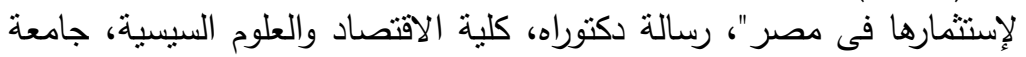

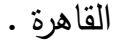

المؤسسة العربية لضمان الاستثمار (999 1) ،"الاستثمار الأجنبى المباشر والتتمية"، سلسلة

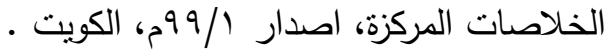

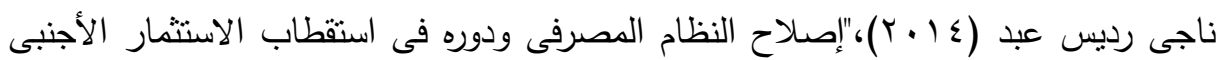
المباشر - دراسة نظرية "، المجلة العلمية للاقتصاد والتجارة، العدد الأول، كلية التهاية

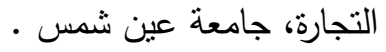

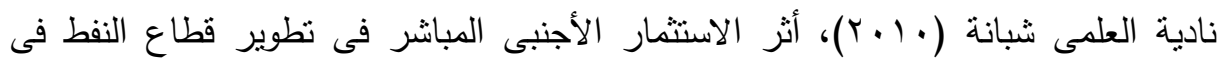

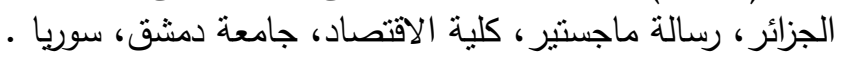

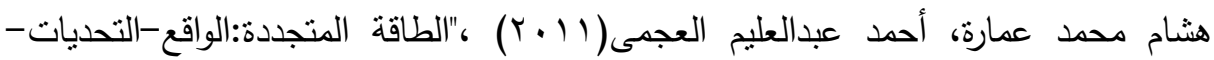

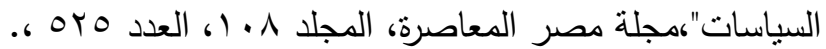

$$
\begin{aligned}
& \text { المجلد التاسع والأربعون، العدد الثاني عشر ، جزء (V) ديسمبر •r.r. }
\end{aligned}
$$

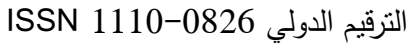


وحيد محمد مهدى عامر، "المتغيرات الاقتصادية فى الاقتصاد المصرى وأثرها فى جذب الأب الأبل الاستثمار الأجنبى المباشر "، المجلة العلمية للاقتصاد والتجائة التهارة، العدد الأول،

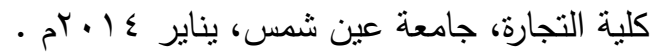

Okposin, Samuel B., and Adebola Temitope Amalu(2015). "Government Regulation of Foreign Direct Investment Inflow and Sustainable Development in Sub-Saharan Africa.".

Asiedu, Elizabeth(2006). "Foreign direct investment in Africa: The role of natural resources, market size, government policy, institutions and political instability." The World Economy 29.1.

Hoda Abdel Moneim Hassaballa(2011),Environment and Foreign Direct Investment:An Empirical Investigation , PhD ,Department of Economics , Faculty of Economics and Political Science, Cairo University.

للبنك

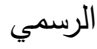

الموقع

$$
\text { الدولي: }
$$

،http://data.albankaldawli.org/indicator/BX.KLT.DINV.CD.WD

$$
\text { تاريخ زيارة للموقع r-r-r-r.r.r. }
$$

استراتيجية التتمية المستخامة هب • rمthtp://www.mop.gov.eg/Vision/EgyptVision.aspx

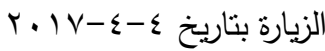

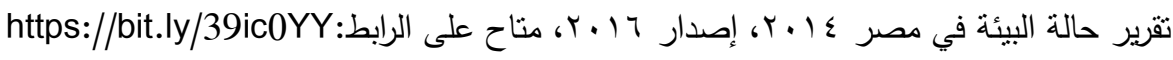

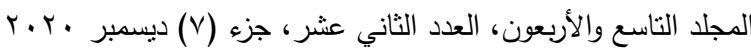

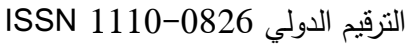




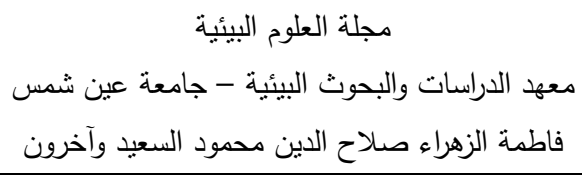

\title{
ROLE OF FOREIGN DIRECT INVESTMENT IN THE
} FIELD OF RENEWABLE ENERGY IN EGYPT

\section{Fatama Al-Zahraa S. M. EL-Saied ${ }^{(1)}$; Elsayed A. abdelwahed $^{(2)}$; and Essam M. Elgenady ${ }^{(3)}$}

1) Institute of Environmental Studies and Research, Ain Shams University 2) Economics And Public Finance Department,Faculty of Law, Ain Shams University 3) Mechanical Engineering Department, Arab Academy for Science, Technology and Maritime Transport.

\begin{abstract}
Egypt is aiming at increasing the share of renewable energy from the total energy production in 2035 sustainable energy strategy of the country. Renewable energy production is planned to cover $20 \%$ of the total energy production by 2022 and to reach $42 \%$ by 2035 . At the same time, Egypt is seeking to attract more foreign direct investments in order to help the country's economy. The present work aims at studying the role of foreign direct investment in the field of renewable energy in Egypt during the period from 2009 to 2019. The present study adopted the inductive approach, and the methodology included four steps: 1) determination of the required data, 2) Identification of the entities responsible for providing the required data, which is the General Authority for Investment and Free Zones (GAFI), the New and Renewable Energy Development and Use Authority (NREA), and the Holding Company For Egypt Electricity and also the Hydro Power Plant Executive Authority (HPPEA), 3) Officially addressing these authorities to obtain the required data, 4) Data processing and interpretation. Main findings of the study include: 1) Results showed that the industrial sector had the largest share of foreign direct investment during the study time frame followed by finance sector,
\end{abstract}

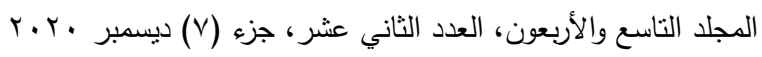

$$
\begin{aligned}
& \text { الترقيم الدولي 0826-1110 }
\end{aligned}
$$




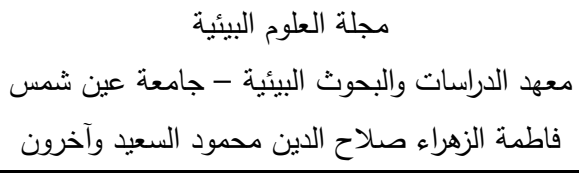

services sector, structural sector, agricultural sector, telecommunications and information technology sector while tourism sector came at the last position, 2) Egyptian contribution to the field of traditional energy such as power stations and petroleum services exceeds the contribution of foreigners by $84 \%$ of the total investment in this field, 3) The contribution of foreigners in the field of renewable energy in government projects exceeds the contribution of Egyptians by $77 \%$, while in private sector projects, the contribution of foreigners exceeds that of Egyptians by $88 \%$ of the total investments in these projects, 4) There are 40 foreign countries investing in Egypt in the field of renewable energy, and the Netherlands alone accounts for 52\% of the total foreign direct investment in the field of renewable energy in Egypt. The present study recommends the necessity of linking foreign direct investment plans with sustainable development plans. A more indepth study of Egypt's potentialities in the field of renewable energy and relying upon it to attract more foreign direct investment is highly recommended. Databases connected the subject of concern at the relevant authorities should be connected and well-built and allowed for researchers which in return will help the country in better understand the needs and improvements that may be considered in future plans.

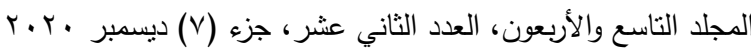

$$
\begin{aligned}
& \text { الترقيم الدولي 0826-1110 }
\end{aligned}
$$

